\title{
Modelling conjugate flow and heat transfer in a ventilated room for indoor thermal comfort assessment
}

\author{
Kana Horikiri ${ }^{1}$, Yufeng $\mathrm{Yao}^{2, *}$, Jun $\mathrm{Yao}^{3}$
}

${ }^{1}$ Faculty of Science, Engineering and Computing, Kingston University, London SW15 3DW, United Kingdom

${ }^{2}$ Faculty of Environment and Technology, University of the West of England, Bristol BS16 1QY, United Kingdom

${ }^{3}$ School of Engineering, University of Lincoln, Brayford Pool, Lincoln LN6 7TS, United Kingdom

*Corresponding author. Tel.: +44 1173287084

E-mail address: Yufeng.Yao@uwe.ac.uk

\section{$\underline{\text { Abstract }}$}

Conjugate natural and forced convection heat transfers in a domestic model room of finitethickness walls and a heat source have been numerically studied. A 2-D non-ventilated square model room with a heat source is investigated at first for conditions of Prandtl number $\operatorname{Pr}=0.7$ and Grashof number $G r=10^{7}$. Computational results are compared with already validated numerical predictions and good agreement has been achieved in terms of stream function and temperature distributions. The study continues to consider 3-D ventilated rectangular model room with a finite-thickness wall and a heat source, in order to evaluate flow and heat transfer characteristics. Key physical features such as temperature distributions in both solid wall and indoor air domains, and heat transfer performance have been quantified, analysed and compared. These results provide the correlations among room heating device arrangement, wall thickness effect, indoor thermal comfort level and energy 
consumption. It was found that the arrangements of heat source and window glazing had significant impact on the temperature field, and further analysis of wall thickness and thermal conductivity variations revealed the level of the comfort temperature within the occupied zone. It was also found that for an average $U$-value of $0.22 \mathrm{~W} / \mathrm{m}^{2} \mathrm{~K}$, thermal energy loss through a thinner wall of $20 \mathrm{~cm}$ thickness is $53 \%$ higher and indoor thermal temperature is $4.6{ }^{\circ} \mathrm{C}$ lower, compared with those of a thicker wall of $40 \mathrm{~cm}$ thickness. The findings would be useful for the built environment thermal engineers in design and optimisation of domestic rooms with a heat source.

Keywords: Computational fluid dynamics; Conjugate heat transfer; Natural and forced convection, Indoor environment; Thermal comfort.

\section{Introduction}

Analysis of conjugate natural and forced convective flows and heat transfer performance of built environment has been an interesting research subject. It is because of its technical applications in design and layout of indoor thermal devices, heat storage systems and indoor thermal environment comfort assessment, among many other reasons. However, the coupling of fluid flow and heat transfer would be complex and challenging even for a single natural convection model room. This is due to the nonlinearity of the physical problem itself and also the interactions between the closely related flow field and temperature field. Recently, there have been growing demands from building industry and heating thermal device design sector in analysing and quantifying accurate information of flow and thermal characteristics of a typical indoor environment for human beings. One of many key steps towards the ultimate goal of eco- or smart-building design is to have a thorough understanding of flow and heat transfer phenomena in relation to thermal heat sources and layout, material properties and 
boundary conditions of room walls and surfaces. This is because they will have a major influence on indoor thermal comfort level including air quality and heating/cooling loads. The present research intends to address some of these pressing issues by using a conjugate heat transfer (CHT) computational fluid dynamics (CFD) approach.

Past researches were primarily focused on the heat transfer and thermal effects in a relatively simple two-dimensional (2-D) model room such as an enclosed domain without a heat sink. Their investigations were performed on flow patterns, fluid temperature distributions and the relation of Nusselt number $(\mathrm{Nu})$ and Rayleigh number $(\mathrm{Ra})$ with respect to heated walls or heating systems [1-5]. A common conclusion from these studies was that at a $R a$ number, $R a \leq 10^{7}$, the heat transfer performance in terms of Nusselt number is proportional to Rayleigh number and also dependent on the thermal conductivity ratio of the fluid and the solid. Similar findings were reported in studies of different 2-D conjugate natural convection configurations [6-7], in which the addition of a vertical heated plate would significantly reduce the heat transfer rate, from about $40 \%$ for thin walls to about $12 \%$ for thick walls [6]. For large Grashof number $>10^{5}$, the temperature inside the finite-thickness wall was broadly of two-dimensional distribution and the non-uniform distributed temperature on the solid-fluid interfaces would cause asymmetric flow patterns [1]. The distribution of heat flux was also affected by surface radiation emissivity, wall conductivity ratio, and wall thickness [8]. In the conjugate mixed convection study, it was revealed that the locations of vertical heat source and horizontal ventilation opening slot would have major influences on the strength and pattern of flow circulation and the level of heat transfer [9]. Despite most of the two-dimensional conjugate heat transfer studies have shown basic fluid flow and heat transfer characteristics using stream lines and heat lines [10-11], there are limited studies on modelling more general and complicated flow and heat transfer features in a three- 
dimensional (3-D) configuration. Furthermore, there are not many studies on analysing the relationships between indoor thermal condition and conjugate conduction and convection heat transfer performance.

For a general 3-D problem such as the evaluation of thermal comfort level in an indoor environment, the physics behind the fluid dynamics and the heat transfer would be complex, because of the nonlinearity and time-dependence of the problem. For example, in the cold Winter season, a ventilation system is required to improve the indoor thermal conditions of the room, as well as to improve the air quality by air circulation. Thus, the interaction between the 'cold' airflow from the ventilation system intake and the 'warm' airflow from the heating systems would have significant effect on heat transfer characteristics that will ultimately impact on the thermal comfort level [12], the flow structures [13] and air quality [14]. The studies on thermal comfort level have been conducted experimentally and numerically by investigating ventilation systems for ventilation effectiveness [15-18] and air distribution [19]. Other factors that affect indoor environment are wall thickness and thermal insulations [20], glazing systems [21-22], fluid temperature of heat sources [23], and radiant temperature [24].

The traditional approach of building a dedicated physical test room or even a complete test house for onsite real-time measurement of key physical parameters such as temperature of the fluid (air) and the solid wall is still valid and vital for providing accurate reference data for building thermal design engineers. However, this approach would be very expensive and time consuming, and also the measured data are often limited, so that they cannot be easily applied for some specific configurations [25]. 
With the advancement of numerical method and computational power, modern CFD techniques provide an alternative way of obtaining 3-D time-dependent flow and thermal parameters at both system and component levels. Furthermore, CFD can produce much detailed information to optimise an existing or a future thermal design and to perform thermal comfort assessment of an indoor environment [12,26-27]. The fast growing computer technology and architecture such as multi-core CPU and GPU make CFD even more feasible to carry out vast number of parametric studies (for which it is almost impossible with physical tests and measurements due to extremely high computing time and cost requirements). With CFD, it is able to predict the performance of a new design concept, before it is going to physical prototyping and manufacturing stages [28-29]. For these reasons, numerical predictions have increasingly become an important element integrated in any engineering design and analysis for cost saving, durability and reduced time scale from product design to market.

Building on previous success of validation and verification exercises of several benchmark test cases including natural convection in a tall cavity [30] using a commercial CFD code ANSYS Fluent [31], present study further investigates the conjugate heat transfer in a 2-D non-ventilated natural convection model room with a heating source and a 3-D ventilated forced convection model room with a heating source and window glazing. Details of flow and heat transfer characteristics will be carried out with parameters including the location of the heating source, the wall thickness and the wall thermal conductivity effects on indoor thermal condition such as comfort temperature as well as energy consumption. The employed mathematical models and numerical schemes will be carefully tested and compared with other already validated numerical predictions and theoretical calculations $[5,12,32]$. 


\section{Description of governing equations and models}

\subsection{Governing equations}

\subsubsection{Fluid domain}

The fluid flow and heat transfer is governed by a set of conservation equations (mass, momentum and energy). The momentum Navier-Stokes equation is used for laminar flow in 2-D problem and Reynolds-averaged Navier-Stokes (RANS) equation is adopted for turbulent flow in 3-D problem. These equations are expressed in a general Cartesian form as follows:

Mass conservation equation

$\frac{\partial \rho}{\partial t}+\nabla \cdot(\rho \vec{v})=0$

Momentum conservation equation

$\frac{\partial}{\partial t}(\rho \vec{v})+\nabla \cdot(\rho \vec{v} \vec{v})=-\nabla p+\nabla \cdot(\overline{\bar{\tau}})+\rho \vec{g}+\vec{F}$

Energy transport equation

$\frac{\partial}{\partial t}(\rho E)+\nabla \cdot[\vec{v}(\rho E+p)]=\nabla \cdot\left(k_{e f f} \nabla \mathrm{T}-\sum_{j} h_{j}^{*} \vec{\jmath}_{j}+\left(\overline{\bar{\tau}}_{e f f} \cdot \vec{v}\right)\right)+S_{h}$

where $t$ is time, $\rho$ is density $\left(\mathrm{kg} / \mathrm{m}^{3}\right), \nabla$ is partial differentiation operator, $\vec{v}$ is velocity vector, $p$ is pressure $(P a), \rho \vec{g}$ is gravitational body force vector and $\vec{F}$ is other external body force vector, $E$ is total energy $(W), k_{e f f}$ is effective heat conductivity $(W / m K), T$ is temperature, $h^{*}$ is sensible enthalpy, $\int_{T_{r e f}}^{T} c_{p} d T(J), c_{p}$ is specific heat at constant pressure 
$j / \mathrm{kgK}, \vec{J}_{j}$ is diffusion flux of species $j, \overline{\bar{\tau}}_{e f f}$ is effective stress tensor, $S_{h}$ is an additional energy source due to chemical reaction or radiation. The term of $\overline{\bar{\tau}}$ is written as

$\overline{\bar{\tau}}=\mu\left[\left(\nabla \vec{v}+\nabla \vec{v} \mathrm{~T}^{*}\right)-\frac{2}{3} \nabla \cdot \vec{v} I^{*}\right]+S_{\text {turbulent }}$

where $\mu$ is viscosity $(\mathrm{kg} / \mathrm{sm}), T^{*}$ is matrix transpose, $I^{*}$ is unit tensor, $S_{\text {turbulent }}$ is Reynolds stress term for turbulent flow $\left(S_{\text {turbulent }}=\nabla \cdot\left(-\rho \overline{v^{\prime} v^{\prime}}\right)\right.$, where $-\rho \overline{v^{\prime} v^{\prime}}$ is Reynolds stress tensor).

\subsubsection{Solid domain}

The temperature distribution within the solid region is governed by 1-D heat conduction equation as

$\nabla^{2} \mathrm{~T}=0$

\subsubsection{The interface between fluid region and solid region}

At the interface between fluid region and solid region in the conjugate heat transfer model, the conductive heat transfer throughout the solid is coupled with the convective heat transfer in the fluid by

$(\nabla \theta)_{\text {fluid }}=\frac{\mathrm{k}_{\mathrm{wall}}}{\mathrm{k}}(\nabla \theta)_{\mathrm{wall}}$

where $\theta$ is dimensionless temperature and $k_{\text {wall }}$ is wall thermal conductivity. 


\subsection{Radiation model}

Due to the existence of a heating source in the computational domain, radiation heat needs to be included in the energy equation (3) via the source term $S_{h}$. In present study, a Discrete Ordinates (DO) model [33] is adopted and it has been already implemented in ANSYS Fluent software by incorporating the enthalpy balance to account for radiative heat transfer from a given heating source to adjacent medium (e.g. fluid) via a finite number of trajectories, each associated with a vector direction $\vec{s}$ defined in the global Cartesian coordinate system. The solution of DO model is similar to that of fluid flow and energy transport equations and the resultant heat flux will be coupled with the energy equation through source term $S_{h}$ in Eq. (3). In the DO model, the radiative heat transfer equation for an absorbing, emitting, and scattering medium at a position $\vec{r}$ in the direction $\vec{s}$ is given by

$\nabla(I(\vec{r}, \vec{s}) \vec{s})+\left(a+\sigma_{s}\right) I(\vec{r}, \vec{s})=a n^{2} \frac{\sigma T^{4}}{\pi}+\frac{\sigma_{s}}{4 \pi} \int_{0}^{4 \pi} I\left(\vec{r}, \vec{s}^{\prime}\right) \Phi\left(\vec{s}, \vec{s}^{\prime}\right) d \Omega^{\prime}$

where $I$ is radiation intensity $(W / s r)$ and is dependent on the position $\vec{r}$ and the direction $\vec{s}$, $a$ is absorption coefficient, $\sigma_{s}$ is scattering coefficient, $n$ is refractive index, $\sigma$ is StefanBoltzmann constant $\left(5.669 \times 10^{-8} \mathrm{~W} / \mathrm{m}^{2} \mathrm{~K}^{4}\right), \Phi$ is phase function and $\Omega^{\prime}$ is solid angle $(s r)$.

\subsection{Turbulence model}

The transport equations for the two-equation renormalized group RNG $k$ - $\varepsilon$ turbulent model [34] are described below.

$\frac{\partial}{\partial t}(\rho k)+\nabla(\rho k \vec{v})=\nabla\left(\alpha_{k} \mu_{e f f} \nabla k\right)+G_{k}+G_{b}-\rho \varepsilon-Y_{M}+S_{k}$ 
$\frac{\partial}{\partial t}(\rho \varepsilon)+\nabla(\rho \varepsilon \vec{v})=\nabla\left(\alpha_{\varepsilon} \mu_{e f f} \nabla \varepsilon\right)+C_{1 \varepsilon} \frac{\varepsilon}{k}\left(G_{k}+C_{3 \varepsilon} G_{b}\right)-C_{2 \varepsilon} \rho \frac{\varepsilon^{2}}{k}-R_{\varepsilon}+S_{\varepsilon}$

where $k$ is turbulence kinetic energy, $\mu_{e f f}$ is effective viscosity, $\varepsilon$ is turbulence dissipation rate, $G_{k}$ is turbulence kinetic energy generation with respect to mean velocity gradients, $G_{b}$ is turbulence kinetic energy generation with respect to buoyancy, $Y_{M}$ is dilatation dissipation, $C_{1 \varepsilon}, C_{2 \varepsilon}, C_{3 \varepsilon}$ are constants, $\alpha_{k}, \alpha_{\varepsilon}$ are inversed 'effective' Prandtl numbers for $k$ and $\varepsilon$, and $S_{k}, S_{\varepsilon}$ are source terms. The $R_{\varepsilon}$ term accounts for the effect of rapid strain and streamline curvature change.

\subsection{Geometrical and physical parameters and dimensionless variables}

For 2-D and 3-D case studies presented thereafter, lengths in horizontal (streamwise $x$ ), vertical (wall normal $y$ ) and lateral (spanwise $z$ ) directions are denoted as $L, H, W$, respectively and non-dimensional coordinates are $X=x / L, Y=y / H, Z=z / W$. In order to compare simulation results calculated in this study with those obtained by other researchers, following dimensionless physical variables are adopted.

$\theta=\frac{\left(T-T_{0}\right) k_{r a d}}{q_{0} L^{2}}$

or

$\theta=\frac{T-T_{0}}{T_{\text {rad }}-T_{0}}$

$\Psi=\psi \sqrt{\frac{k_{r a d}}{g \beta q_{0} L^{5}}}$ 
where $\theta$ is dimensionless temperature, $T_{0}$ is initial temperature, $k_{\text {rad }}$ is thermal conductivity of radiator panel, $q_{0}$ is volumetric thermal-power density of heat source $\left(\mathrm{W} / \mathrm{m}^{3}\right), L$ is streamwise length of fluid domain $(m), \Psi$ is dimensionless stream function, $\psi$ is stream function $\left(\mathrm{m}^{2} / \mathrm{s}\right), \mathrm{g}$ is gravity $\left(\mathrm{m}^{3} / \mathrm{s}\right)$ and $\beta$ is thermal expansion coefficient. Note that Eq. (10a) is used to calculate dimensionless temperature for the 2-D case with heat generation boundary condition in 2-D case, while Eq. (10b) is used for the 3-D case with temperature boundary condition.

Other physical parameters used throughout the studies are

$$
\operatorname{Pr}=\frac{v}{\alpha}
$$

$G r=\frac{g \beta q_{0} L^{5}}{v^{2} k_{\text {rad }}}$

or

$G r=\frac{g \beta \Delta T L^{3}}{v^{2}}$

where $\operatorname{Pr}$ is Prandtl number, $v$ is momentum diffusivity, $\alpha$ is thermal diffusivity $\left(\mathrm{m}^{2} / \mathrm{s}\right), G r$ is Grashof number and $\Delta T$ is temperature difference. Note that similar to variable $\theta$, Eq. (13a) and (13b) are used for 2-D and 3-D case studies, respectively. 


\subsection{One-dimensional heat conduction in a large plane wall}

For a large plane wall, one-dimensional (1-D) heat conduction equation can be applied and using the Fourier's law, the equation can be written as

$$
Q_{\text {cond }}=-k A \frac{d T}{d x}
$$

where $Q_{\text {cond }}$ is conductive heat transfer, $k$ is thermal conductivity of solid material, $d T / d x$ is the temperature gradient, and $A$ is the heat conduction area $\left(m^{2}\right)$. Thus, the total and surface heat fluxes can be evaluated by

$q_{\text {total }}=\frac{T_{\text {in }, \infty}-T_{\text {out }, \infty}}{R_{\text {total }}}$

$q_{\text {surface }}=h_{\text {in or out }}\left(T_{\text {in or out }, \infty}-T_{\text {inner or outer surface }}\right)$

where $q_{\text {total }}$ is total heat flux $\left(\mathrm{W} / \mathrm{m}^{2}\right), R_{\text {total }}$ is total thermal resistance (i.e., $R$-value) $\left(m^{2} K / W\right), q_{\text {surface }}$ is surface heat flux, $h$ is heat transfer coefficient $\left(W / m^{2} K\right)$ and indexes in and out are internal and external environments, subscript $\infty$ is ambient condition and inner surface and outer surface are internal and external surfaces of a finite-thickness wall.

An energy balance over a wall thickness of $\Delta x$ within a small time interval (i.e. before thermal equilibrium fully established) can be expressed as

$$
\frac{1}{A} \nabla(k A \nabla T)+\dot{e}_{g e n}=\rho c_{p} \nabla T
$$


Where $\dot{e}_{g e n}$ is heat generation per unit volume $\left(W / \mathrm{m}^{3}\right)$.

By considering a constant thermal conductivity (which is generally valid for most practical applications), steady-state heat transfer and no extra heat generation inside the solid domain, Eq. (16) can be further simplified to a Laplace equation of temperature (Eq. (5)).

By defining proper boundary conditions at computational domain boundaries, this Laplace equation can be discretised and solved in a straightforward manner, resulting the conduction heat as a linear function of streamwise position, i.e. $T=m x+n$, where constant parameters ( $m$ and $n$ ) are determined by boundary conditions.

\section{Numerical methods}

The aforementioned equations are solved numerically by finite volume method on uniform structured grid. An iterative solution method, SIMPLE algorithm [35], is employed to solve the nonlinearity of the momentum equation, the velocity-pressure coupling and the coupling between the flow and the energy equations. For pressure Poisson equation, the solution applies weighted body-force under the assumption that the gradient of the difference between the pressure and body forces is constant, especially in buoyancy calculations. Other equations such as momentum, energy and radiation are solved using the second-order numerical scheme. For a two-dimensional case study, laminar viscous model is used due to low Reynolds number and for a three-dimensional case study; turbulent viscous flow model is adopted with two-equation renormalized group (RNG) $k-\varepsilon$ turbulence model. The Discrete Ordinates (DO) radiation model is applied with various angular discretisation and subiteration parameters to control angles in discretising each octant of the angular space and 
volume overhang on each surface respectively, so that radiative conditions can be applied to individual faces and fluid within the domains. In both 2-D and 3-D cases, numerical accuracy of double precisions are defined and the residual target is defined as $10^{-12}$ to achieve a high level of accuracy.

\section{Validation}

The validity of numerical models has been assessed for a 2-D model problem including streamlines $(\Psi)$ and isotherms $(\theta)$ at different Grashof numbers and corresponding stream function and temperature distributions at different cross-sections of the domain, and for a 3-D physical room model including the dimensionless comfort temperature ( $\left.\theta_{\text {comfort }}\right)$ distribution at several monitoring points in the domain and the heat transfer performances of the heat source (i.e. the radiator), respectively.

\subsection{Two-dimensional closed model room with a heat source}

\subsubsection{General description of the 2-D model}

A two-dimensional model room with conjugate natural convection heat transfer has been chosen for validation against available numerical results obtained by Kuznetsov and Sheremet [5] using finite-difference CFD approach. It is a square closed model room (i.e. no ventilation, thus natural convection only) with uniform finite-thickness bounding walls and a localised heat source (see Fig. 1). The heat source is similar to a radiator panel which has a constant uniform volumetric thermal-power density throughout the computation. It is located at the internal surface of the left-side wall. The external surface of this wall $(x=0)$ is directly exposed to external environment. Other three walls $\left(x=x_{\max }, y=y_{\min }\right.$ and $\left.y_{\max }\right)$

are assumed to be adiabatic without radiation heat exchange (e.g. $\frac{\partial \theta}{\partial n}=0$ where $n$ is dimensionless distance acting normal to the surface in $x$ or $y$ direction). At the solid-fluid 
interface, the velocity components are set to be zero (i.e. no-slip condition). Because of a low Reynolds number, the fluid medium inside the flow domain is incompressible air with laminar viscous flow status. The thermophysical properties of solid walls and fluid (air) are assumed constant.

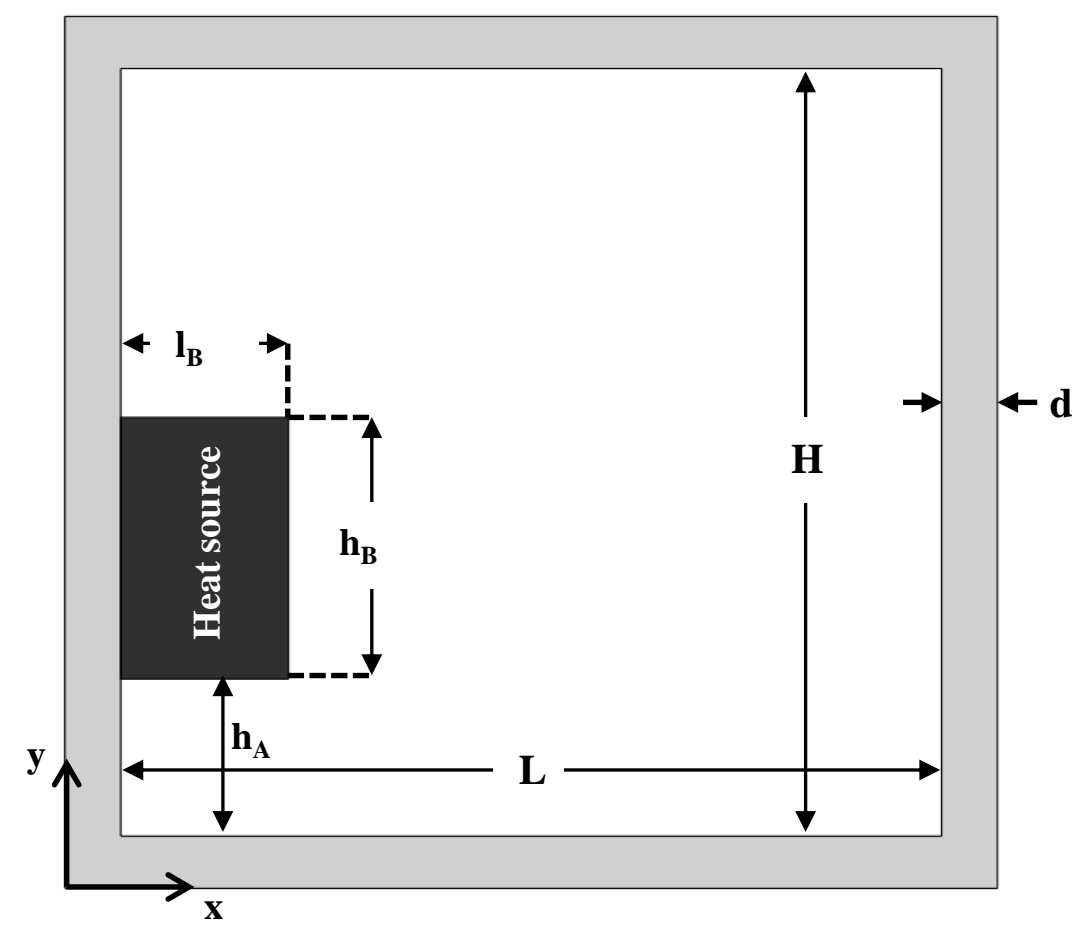

Fig. 1. Schematic view of a 2-D model room.

The model room has dimensions of $H / L=1, d / L=0.06, l_{B} / L=0.18, h_{B} / L=0.3$, $h_{A} / L=0.18$. Two natural convection scenarios are considered at the following conditions; i.e. Prandtl number $\operatorname{Pr}=0.7$, heat conductivity ratio $k_{\text {gas }} / k_{\text {wall }}=3.7 \times 10^{-2}$ and Biot number $B i=2.86$; and scenario 1 has Grashof number $G r=1.6 \times 10^{7}$, dimensionless environment temperature $\theta_{e}=-0.46$ and scenario 2 has $G r=2.4 \times 10^{7}, \theta_{e}=-0.31$. That is equivalent to a wall thermal conductivity of $0.89 \mathrm{~W} / \mathrm{mK}$ and an external environment temperature of $292.8 \mathrm{~K}$ at two given $\mathrm{Gr}$ numbers while an initial temperature is set to be $293 \mathrm{~K}$. Hence, a constant thermal-power density of $12.0 \mathrm{~W} / \mathrm{m}^{2}$ is used for scenario 1 and 
$17.5 \mathrm{~W} / \mathrm{m}^{2}$ for scenario 2 , respectively along with a thermal conductivity of fluid $30.0 \mathrm{~W} / \mathrm{mK}$. The emissivity of all wall surfaces is set to be unity. The dimensionless coordinates are introduced as $X=x / L, Y=y / L$, as stated before.

The grid convergence study has been carried out on three successive meshes of $200 \times 200$, $250 \times 250$ and $300 \times 300$ grid points from coarse to fine and numerical results in terms of temperature and velocity profiles (not shown) have shown no noticeable differences among three meshes, indicating results can be considered grid-independent. Thus, only results from the $200 \times 200$ mesh with uniformly distributed grid points are presented thereafter. The results will be compared with already validated numerical predictions [5] in terms of stream function and temperature at two non-dimensional locations $Y=0.35$ and $Y=0.80$ and at an instantaneous dimensionless time of $\tau=500$ as

$$
\tau=t \sqrt{\frac{g \beta q_{0} L}{k_{\text {rad }}}}
$$

The stream function ( $\psi$ in a unit of $\mathrm{m}^{2} / \mathrm{s}$ ) can be calculated using stream function in a unit of $\mathrm{kg} / \mathrm{s}$ by ANSYS Fluent solver (Eq. (18)) divided by fluid density. The dimensionless stream function $(\Psi)$ is then calculated using Eq. (11) described above.

$$
\rho u \equiv \frac{\partial \psi}{\partial y}, \rho v \equiv \frac{\partial \psi}{\partial x}
$$

where $u$ and $v$ are velocity component. 


\subsubsection{Validation of 2-D room case}

Figure 2 shows streamlines and isotherms from two Grashof numbers at an instantaneous dimensionless time of $\tau=500$. It can be seen that there are two large-scale circulations moving in opposite directions (i.e. counter-rotating) from two cases studied. At $G r=1.6 \times$ $10^{7}$, two similar size circulations are located almost horizontally, with an anti-clockwise circulation lying in the upper part of the domain with positive $\Psi$ value, and a clockwise circulation lying in the lower part of the domain with negative $\Psi$ value, respectively. As Grashof number increases to $G r=2.4 \times 10^{7}$, the clockwise circulation in the lower part of the domain expanded in size in the vertical direction by compressing the anti-clockwise circulation, resulting in a smaller-size anti-clockwise circulation occurred in the upper-left corner region above the heat source. For $G r=1.6 \times 10^{7}$, the strength of the anti-clockwise circulation in the upper part of the domain is about $33 \%$ higher than that of the clockwise circulation (i.e. maximum absolute value of stream function $|\Psi|$ at the core of the circulation). On the other hand, the circulation intensities in $G r=2.4 \times 10^{7}$ differ only by $4 \%$ between the two circulations, despite the flow circulation size is almost halved for the anti-clockwise circulation. The reason for this is probably due to cooling of the upper part of the left-side wall by incoming cold air at $G r=1.6 \times 10^{7}$, which affects the anti-clockwise part of the convective flow. The normalised temperature field (e.g. isotherms) shown in Figs. 2(c) and 2(d) indicates that as Grashof number increases, there is a sign of thermal plume formation in the fluid domain which is stabilized in the upper part of the domain thus causing the increase of conductive heat transfer. This can be seen by the increase of temperature gradient inside the solid wall domain next to the heat source, which may lead to possible unstable stratification effect in the vertical direction above the heat source in the fluid domain. 


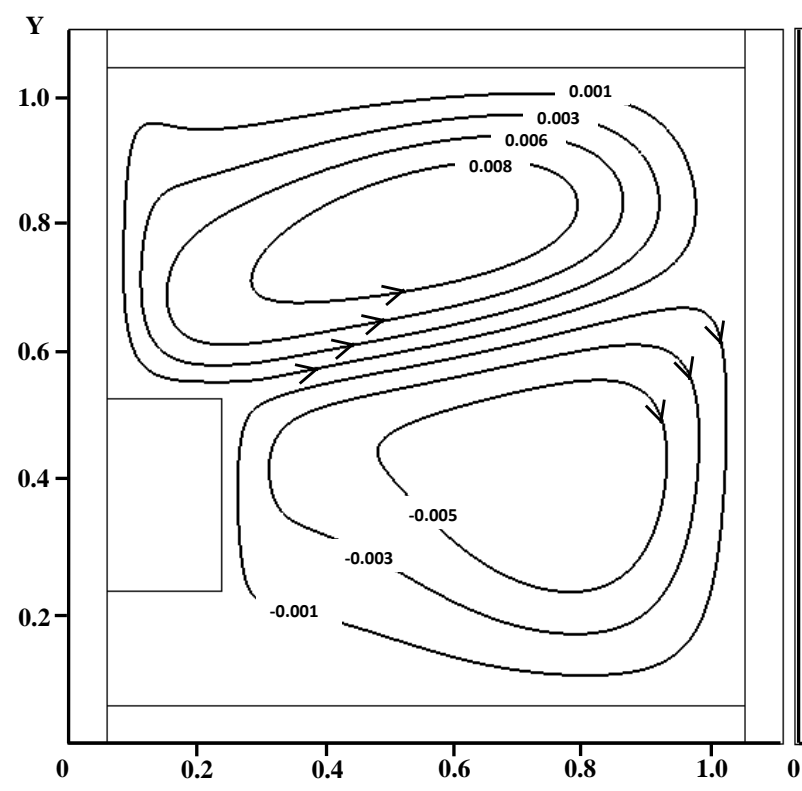

(a)

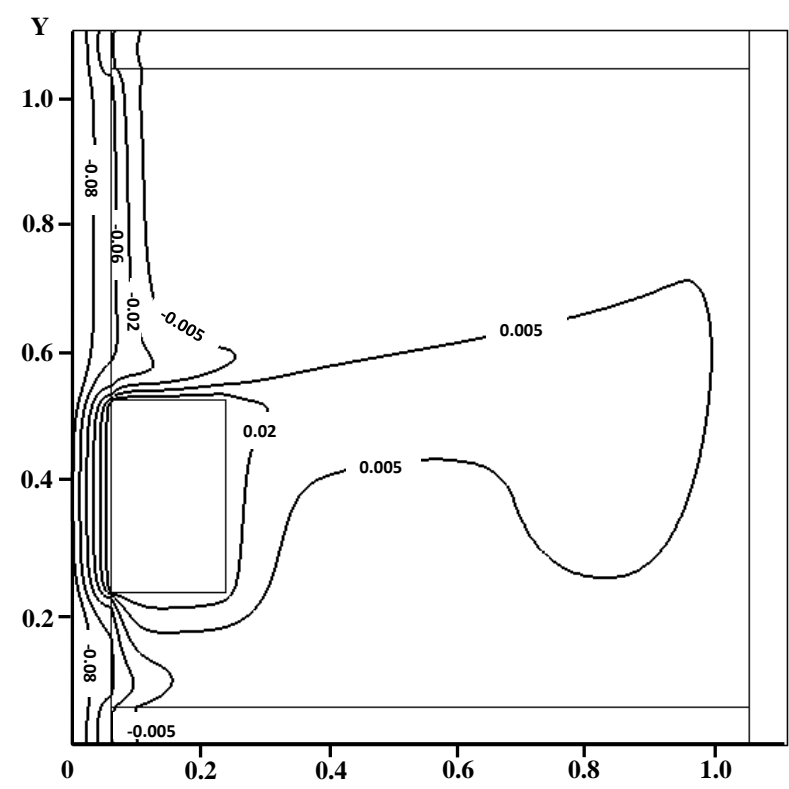

(c)

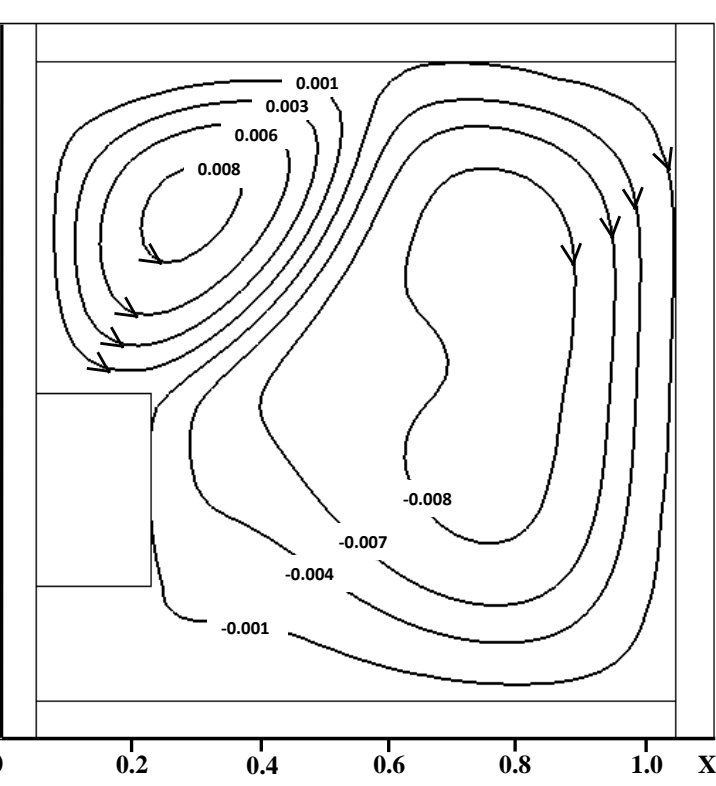

(b)

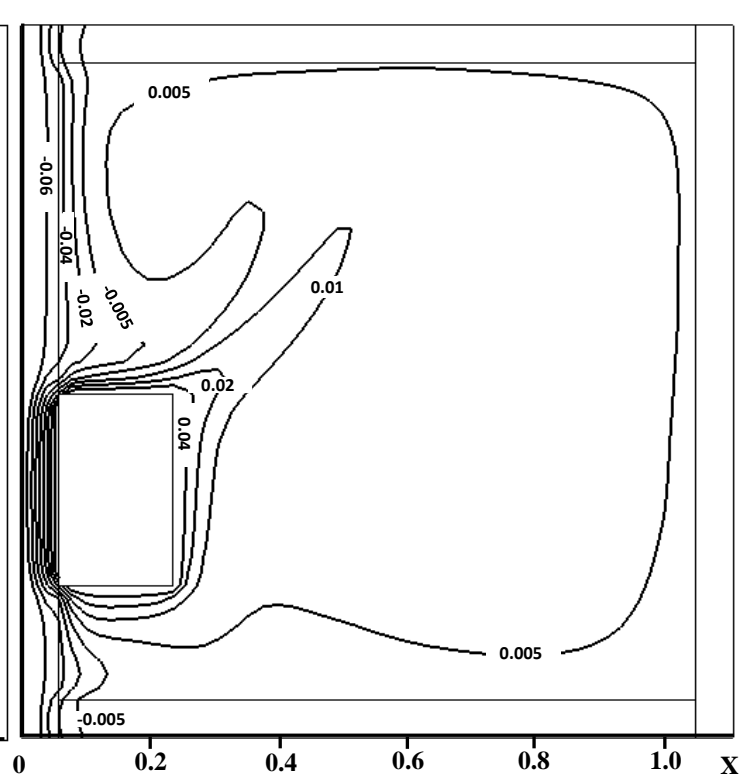

(d)

Fig. 2. Streamlines ( $\Psi)$ and isotherms $(\theta)$ at $\tau=500$ for (a, c) $G r=1.6 \times 10^{7}$ and (b, d) $G r=2.4 \times 10^{7}$.

Figure 3 shows present results at two vertical locations $Y=0.35$ and $Y=0.80$, compared with published data [5]. It is clear that good agreements have been achieved between present computation and previous numerical results [5] in terms of variation shape, pattern and peak 
locations. At a high Grashof number $G r=2.4 \times 10^{7}$, there is only one peak in the stream function magnitude $(|\Psi|)$ at a low position of $Y=0.35$ (see Figure 3(a)), but the shape and distribution of stream function have changed to a near sine wave pattern at a high position of $Y=0.8$, see Fig. 3(b). Comparing to previous predictions by Kuznetsov and Sheremet [5], present results slightly over-predicts the stream function value in a region $X=[0.3,0.6]$ at a low position of $Y=0.35$. The temperature fields in Figs. 3(c) and 3(d) show that temperature rises in both fluid and solid domains as Grashof number increases, due to the increase of the volumetric thermal-power density of the heat source $\left(q_{0}\right)$. This will result in an average temperature increase by $36.3 \%$ on the left-side wall and $45.1 \%$ on the top wall, between two Gr numbers tested. In the solid region $X=[0,0.06]$, the unstable stratification aforementioned can be seen for $G r=2.4 \times 10^{7}$ at $Y=0.8$ and for $G r=1.6 \times 10^{7}$, the predicted temperature is lower than that of previous numerical results [5] at both locations of $Y=0.35,0.8$. At $Y=0.35$, there is a rapid temperature drop adjacent to the heat source which may be due to fast temperature decay when moving away from the radiator. The presence of thermal plume at $G r=2.4 \times 10^{7}$ is also evident by the temperature increase in a region of $0.4<X<1.0$ shown in Fig. 3(d).

Based on the conjugate natural convection heat transfer study for $G r=1.6 \times 10^{7}$ and $2.4 \times 10^{7}$ in a two-dimensional model room, it can be concluded that the increase of Grashof number would lead to the formation of a thermal plume, causing cooling load reduction in the upper part of the fluid domain. Furthermore, this would result in temperature rise in both the solid and the fluid domains and flow-intensification at the core of the circulation magnitude (i.e. $\left.\left|\Psi_{\max }\right|\right)$ strengthened by about $33 \%$ for clockwise circulation and only by about $5 \%$ for anti-clockwise circulation, respectively. 


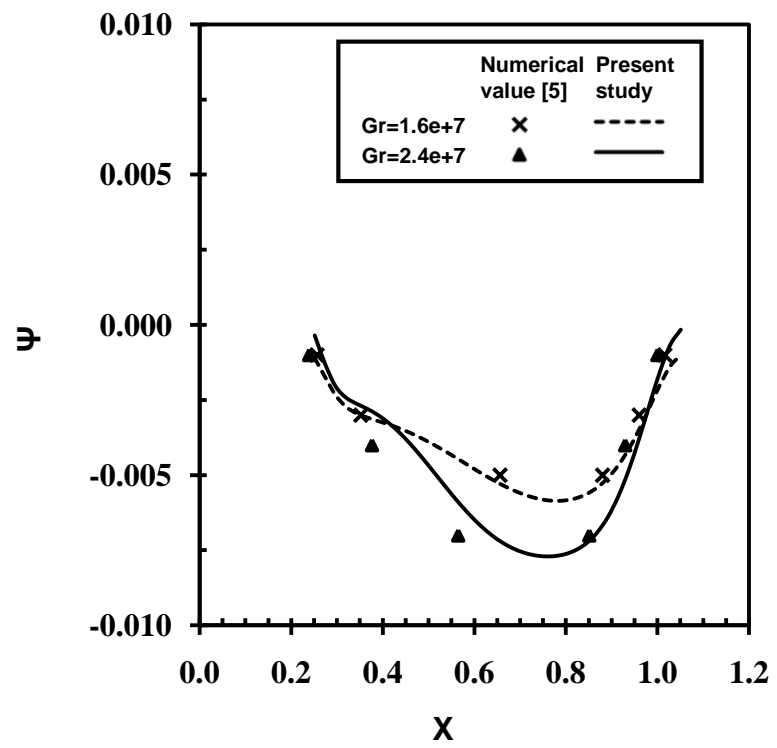

(a)

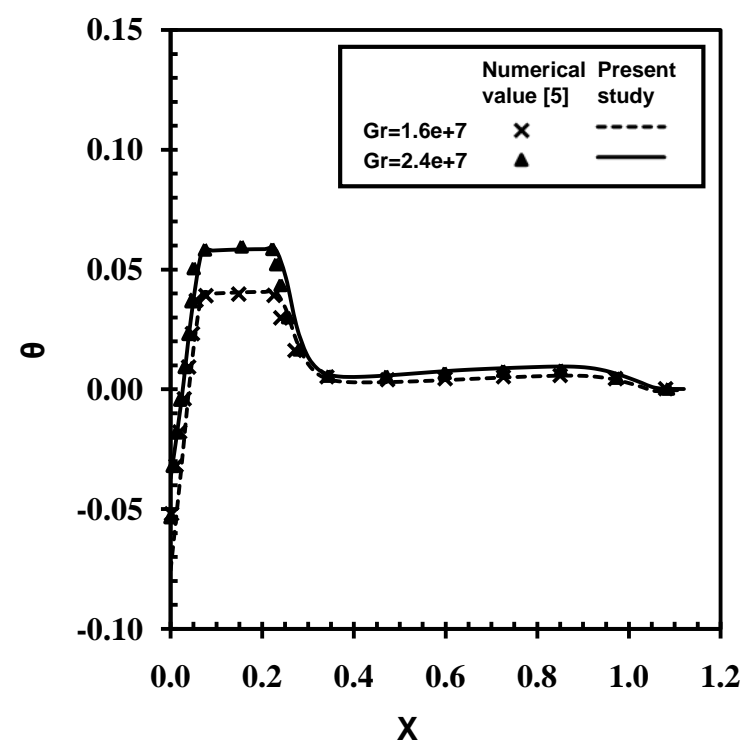

(c)

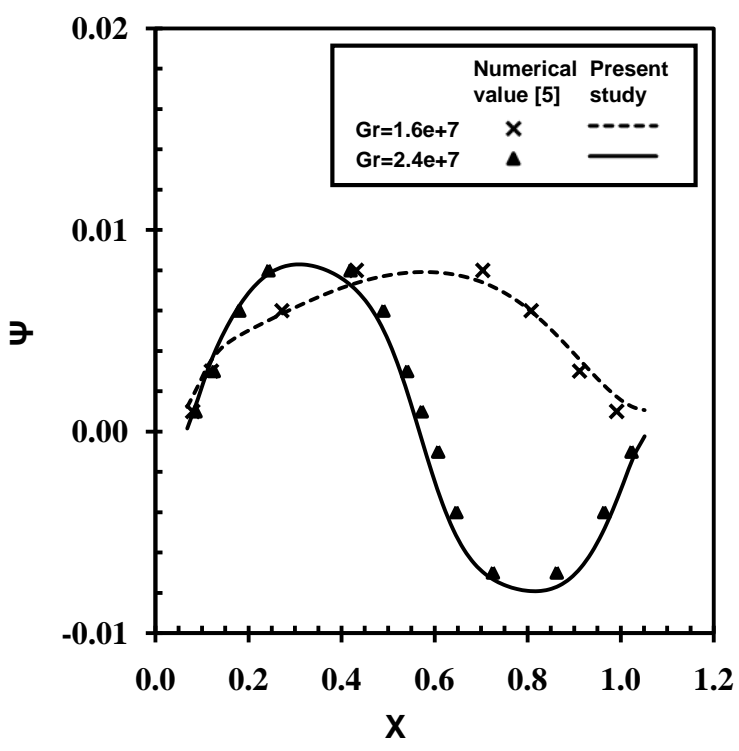

(b)

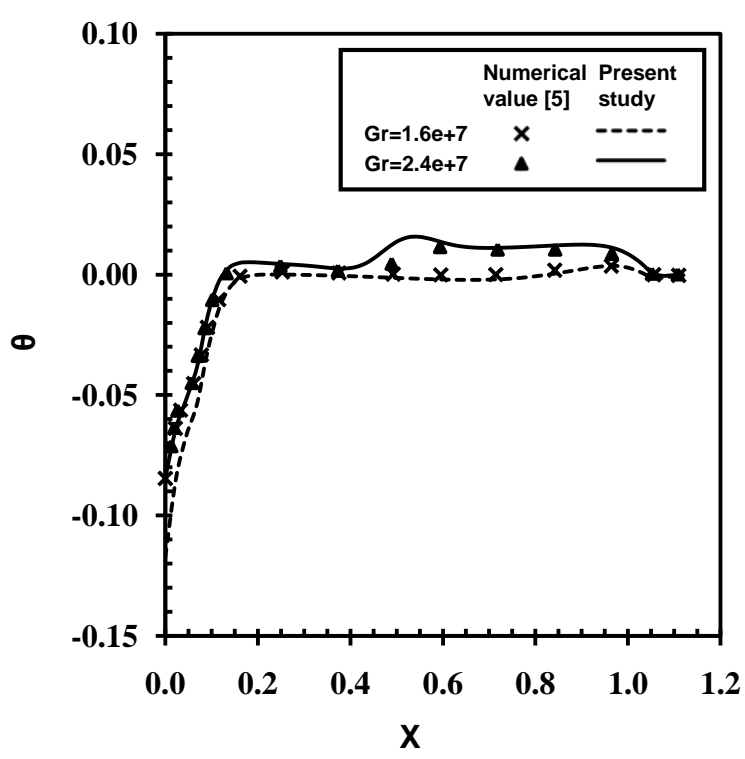

(d)

Fig. 3. Comparisons of stream function and non-dimensional temperature profiles at two $\mathrm{Gr}$ numbers, two vertical locations of $Y=0.35(\mathrm{a}, \mathrm{c})$ and $Y=0.8(\mathrm{~b}, \mathrm{~d})$ and $\tau=500$.

\subsection{Three-dimensional ventilated model room with a heat source}

Based on the validation of a 2-D model room, a 3-D ventilated model room configuration with heating source and window glazing was next studied. 


\subsubsection{General description of 3-D model}

The configuration considered here is a 3-D model room previously studied experimentally by Olesen et al. [16] and also numerically by Myhren and Holmberg [12], see Fig. 4. Although the experiment used finite-thickness solid walls, it was not considered in the numerical study carried out by Myhren and Holmberg [12]. This configuration includes a double panel radiator as heat source, a window, and a ventilation system (i.e. inlet above the window for extracting cold fresh air, and outlet on opposite wall for exhausting warm air), respectively and the model room has dimensions of $L=4.8 \mathrm{~m}, H=2.6 \mathrm{~m}, \mathrm{~W}=2.4 \mathrm{~m}$, resulting aspect ratios of $H / L=0.54, W / L=0.50$. The dimensions and the location of ventilation system, radiator and window glazing can be seen in Table 1. The window wall with inlet duct is directly exposed to the outside environment. The origin of the coordinate system is located at the mid-point of the intersection line between the floor and the inner wall surfaces along the spanwise direction, same as that used by Myhren and Holmberg [12].

Table 1

Specifications of a 3-D model room.

\begin{tabular}{lll}
\hline & Size & Position in room \\
\hline Inlet & Height $h_{3 b} / H=8 \times 10^{-3}$, & Above window at $h_{3 a} / H=0.04$, \\
& Width $W_{\text {inlet }} / W=0.21$ & $h_{3 c} / H=0.18$ from ceiling \\
Outlet & Height $h_{5} / H=0.02$, & On opposite wall, $h_{4} / H=0.06$ down from \\
& Width $W_{\text {outlet }} / W=0.33$ & ceiling \\
Window & Height $h_{2} / H=0.46$, & \\
& Width $W_{\text {window }} / W=1.0$ & \\
Radiator & Height $h_{B} / H=0.23$, & \\
& Width $W_{\text {radiator }} / W=0.58$, & Underneath the window, \\
& Thickness $L_{\text {radiator }} / L=0.01$, & $h_{A} / H=0.02$ above floor and $L_{\text {gap }} / L=0.02$ \\
& Panel gap & from adjacent wall \\
& $L_{\text {panel-gap }} / L=0.008$ &
\end{tabular}


T lists boundary conditions for non-CHT model as those used by Myhren and Holmberg [12]. Present simulation also uses same thermophysical properties of the fluid (air) as that of study [12]. Due to very low speed of incoming cold airflow, incompressible flow assumption is used with $\operatorname{Pr}=0.7$. Based on physical condition of the heat source, i.e. $\operatorname{Gr} / \operatorname{Re}^{2} \gg 1$, and $R e_{\text {inlet }}>700$, the heat transfer due to natural convection will play a major role in the heat transfer process, compared to forced convection mode. The corresponding Rayleigh number ( $R a$ ) is $R a=10^{8}$. The initial indoor temperature is set to be $16{ }^{\circ} \mathrm{C}$ based on an ambient room condition. It assumes that the window wall is a single-layer solid wall with a total $U$-value (i.e. overall heat transfer coefficient) of $0.3 \mathrm{~W} / \mathrm{m}^{2} \mathrm{~K}$ regardless external conditions such as temperature. The window surface also has a fixed temperature of $14{ }^{\circ} \mathrm{C}$.

Table 2

Boundary conditions of non-CHT model.

Inlet Uniform \& constant $T_{\text {air }}=-5{ }^{\circ} \mathrm{C}$ and $U_{\text {air }}=0.7 \mathrm{~m} / \mathrm{s}$

Outlet Naturally outflow

Window Uniform \& constant temperature $T_{\text {window }}=14{ }^{\circ} \mathrm{C}$

Radiator Uniform \& constant temperature $T_{\text {radiator }}=42{ }^{\circ} \mathrm{C}$

Walls Wall exposed to external environment: $U$-value $=0.3 \mathrm{~W} / \mathrm{m}^{2} \mathrm{~K}$, Other walls:

In order to consider the effect of finite-thickness wall used in the experiment, a conjugate heat transfer configuration with a single-layer solid wall structure of width $d / L=0.063$, is introduced for the window wall that is directly exposed to the external environment. Other walls are still treated as infinitely small thickness, same as the study of Myhren and Holmberg [12]. The boundary conditions for the finite-thickness wall are applied with the following assumptions of external environment: the outer surface of the solid wall has the same temperature as external environment $\left(-5^{\circ} \mathrm{C}\right)$ and heat transfer coefficient $h_{\text {out }}=$ 
$34.0 \mathrm{~W} / \mathrm{m}^{2} \mathrm{~K}$ commonly used as the Winter season condition for industrial applications. The external surface of the window also assumes to be the same temperature of the external environment and the window thermal conductivity is defined as $k_{\text {air }} / k_{\text {window }}=0.03$, which gives $k_{\text {window }}$ about $0.9 \mathrm{~W} / \mathrm{mK}$ [32]. The radiation heat exchange is only considered for the finite-thickness window wall.

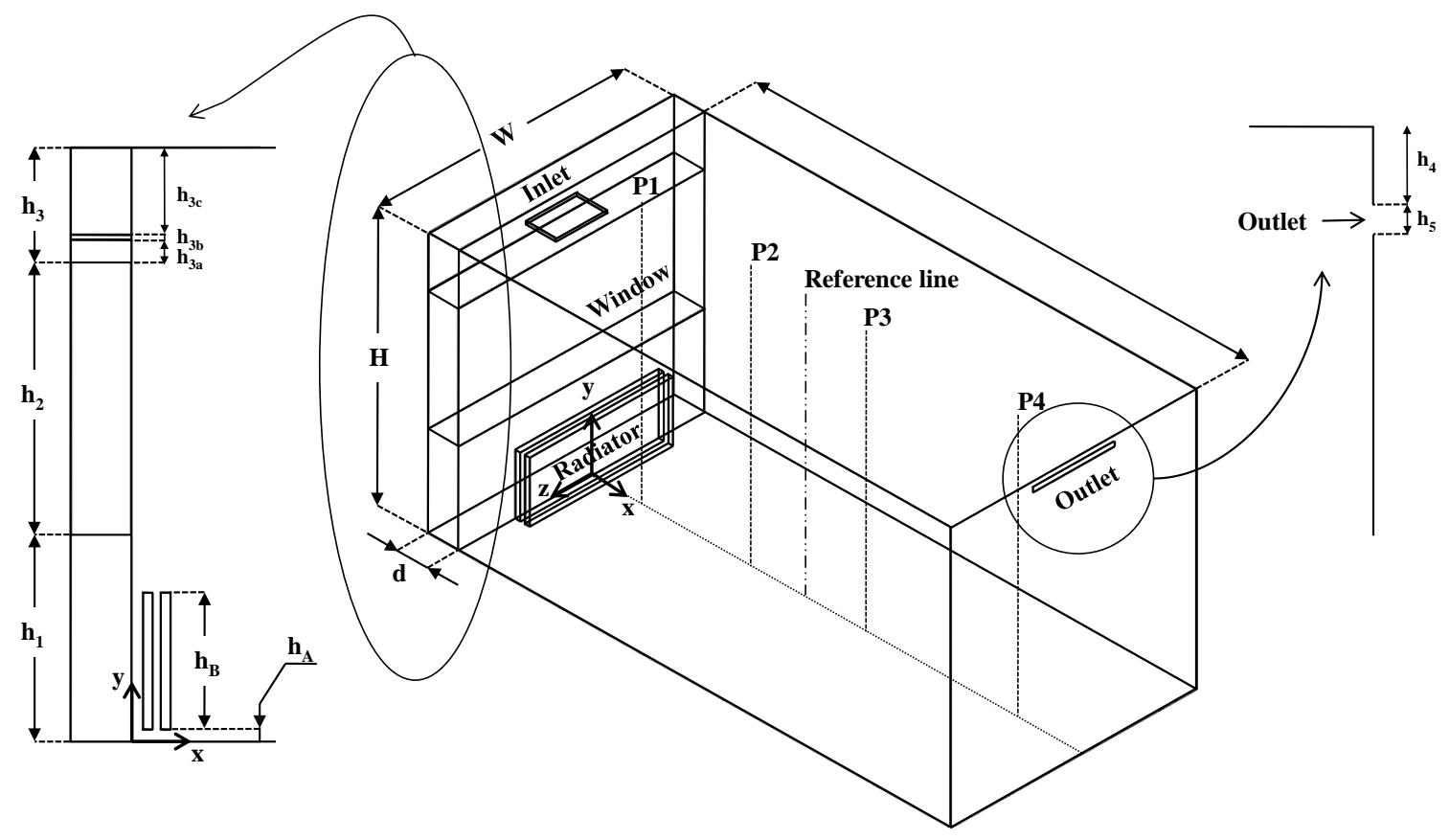

Fig. 4. Schematic view of 3-D configuration.

In order to compare present results with available thermal comfort data obtained by previous experimental and numerical studies $[12,16]$, four monitoring lines are inserted at locations of $L_{P 1} / L=0.125, L_{P 2} / L=0.375, L_{P 3} / L=0.625$ and $L_{P 4} / L=0.875$ from the coordinate origin on a streamwise mid-plane throughout the domain height, i.e. $P 1, P 2, P 3, P 4$ lines, respectively and with a reference line positioned at the centre of the computational domain. The dimensionless coordinates $X, Y, Z$ are defined as $x / L, y / H, z / W$, respectively. 
Steady RANS calculation with the renormalized group (RNG) $k$ - $\varepsilon$ turbulence model is applied, similar to previous studies $[31,36]$. A careful grid convergence study was performed using a block-structured mesh, and the mesh with grid points in a range of 110,000 to 130,000 is finally generated for all test cases presented here.

Due to a high Richardson number $R i=R a /\left(R e^{2} \operatorname{Pr}\right)>1.4 \times 10^{4}$, numerical instabilities in terms of oscillations in convergence history and flow patterns occurred during the steady RANS computation, and the phenomenon is similar to that observed by Raji et al. [13]. Note that $R a$ is Rayleigh number and $R e$ is Reynolds number. This is partly due to the reason that there may exist moderate to strong thermal instabilities caused by the presence of a heat source in the lower region and a ventilation cold airflow in the upper region of the wall, resulting in the formation of a thermal plume and heat exchange between cold and warm airflows inside the domain [37]. Hence, temperature and velocity results are averaged using three sets of time history data at the monitoring lines $P 1-P 4$, with maximum temperature and velocity variations kept within $1^{\circ} \mathrm{C}$ and $0.05 \mathrm{~m} / \mathrm{s}$ range, respectively. The average results are then used to compute the heat transfer of the radiator panels and the room comfort temperature [12,38] by using Eq. (19) see below, for the monitoring points. Results are then compared with available validated data from other numerical studies [12].

$T_{\text {comfort }}=\frac{T_{\text {radiation }}+T_{\text {air }} \sqrt{10 U}}{1+\sqrt{10 U}}$

where $T_{\text {comfort }}$ is comfort temperature, $T_{\text {radiation }}$ is radiation temperature [39] below, $T_{\text {air }}$ is air temperature and $U$ is air velocity magnitude. 
$T_{\text {radiation }}^{4}=\frac{1}{4 \sigma} \int_{0}^{4 \pi} I d \Omega$

where $\Omega$ is solid angle.

\subsubsection{Validation of 3-D room case}

Validation study of steady RANS computations of a 3-D model room with and without conjugate heat transfer are performed and results are compared with theoretical estimation and other numerical results without CHT for the same configuration [12].

Numerical results from present study compared with those from commercial numerical code, FloVENT [12] in terms of fluid temperature and radiator surface heat transfer are shown in Table 3 and with theorerical estimation in terms of solid wall surface temperature and heat transfer shown in Table 4Table. Note that heat tranfer from heat source is computed using formula $Q=Q_{\text {convection }}+Q_{\text {radiation }}$, and that theoretical values in Table 4 are calculated using Eqs. (16a) and (16b) based on numerically calculated heat flux and temperature with the assumption of $T_{\text {out }}=-5{ }^{\circ} \mathrm{C}, U=0.3 \mathrm{~W} / \mathrm{m}^{2} \mathrm{~K}$ and $22{ }^{\circ} \mathrm{C}$ of target ambient indoor temperature, respectively. Also the average of surface temperature is computed using a formula $\bar{\phi}=\frac{1}{A} \int \phi d A$ over a control volume (where $\phi$ is integration variable). It can be seen from Table 3 that the differences between present prediction and those from previous studies are very small in terms of dimensionless temperatures and heat transfer coefficients from the radiator. In general, the non-CHT model predicts temperature slightly lower than that of the CHT model. The present results also show slightly a lower total heat transfer but a significantly higher radiative heat transfer, compared to that obtained by Myhren and Holmberg [12]. There is no noticeable difference between CHT and non-CHT results. Comparison between present prediction and theoretical estimation shows that the predicted 
bottom wall temperature is higher than that of theoretical value, probably due to the existence of heat source next to the wall, and this may result in the higher corresponding wall heat flux and heat transfer of wall, as seen in Table 4. Figure 5 gives the comfort temperature distributions at monitoring lines $(P 1-P 4)$ and reasonably good agreements between three sets of predicted values have been achieved in terms of shape variation, pattern and peak locations, with temperature differences within a small range of $\pm 0.5^{\circ} \mathrm{C}$. The influence of CHT is small near bottom wall region and becomes slightly larger near upper wall region.

Table 3

Comparison of fluid temperature and heat transfer from the radiator.

\begin{tabular}{lccc}
\hline & FloVENT[12] & Non-CHT model & CHT model \\
\hline$\theta_{\text {air }}$ at $1.1 \mathrm{~m}$ level at ref line & 0.56 & 0.56 & 0.58 \\
$\theta_{\text {comfort }}$ at $1.1 \mathrm{~m}$ level at ref line & 0.57 & 0.57 & 0.58 \\
Average $Q_{\text {total }}$ of radiator $(W)$ & 483 & 461 & 461 \\
Average $Q_{\text {radiation }}$ of radiator $(W)$ & 180 & 215 & 221 \\
Average HTC of radiator $\left(W / \mathrm{m}^{2} \mathrm{~K}\right)$ & 6.7 & 6.6 & 6.7 \\
\hline
\end{tabular}

Table 4

Comparison of surface temperature and heat transfer of the wall.

\begin{tabular}{lccc}
\hline & Theory & Non-CHT model & CHT model \\
\hline Mean $\theta_{\text {inner }}$ of top surface of wall & 0.57 & 0.57 & 0.55 \\
Mean $\theta_{\text {inner }}$ of bottom surface of wall & $0.57^{\mathrm{a}}$ & 0.66 & 0.71 \\
Mean $\theta_{\text {inner }}$ of window surface & 0.41 & 0.41 & 0.42 \\
Heat flux through wall $\left(\mathrm{W} / \mathrm{m}^{2}\right)$ & 8.10 & 13.54 & 10.52 \\
Overall HTC through wall $\left(\mathrm{W} / \mathrm{m}^{2} \mathrm{~K}\right)$ & 0.31 & 0.49 & 0.37 \\
\hline
\end{tabular}

${ }^{a}$ based on assumption in section 4.2.2. 


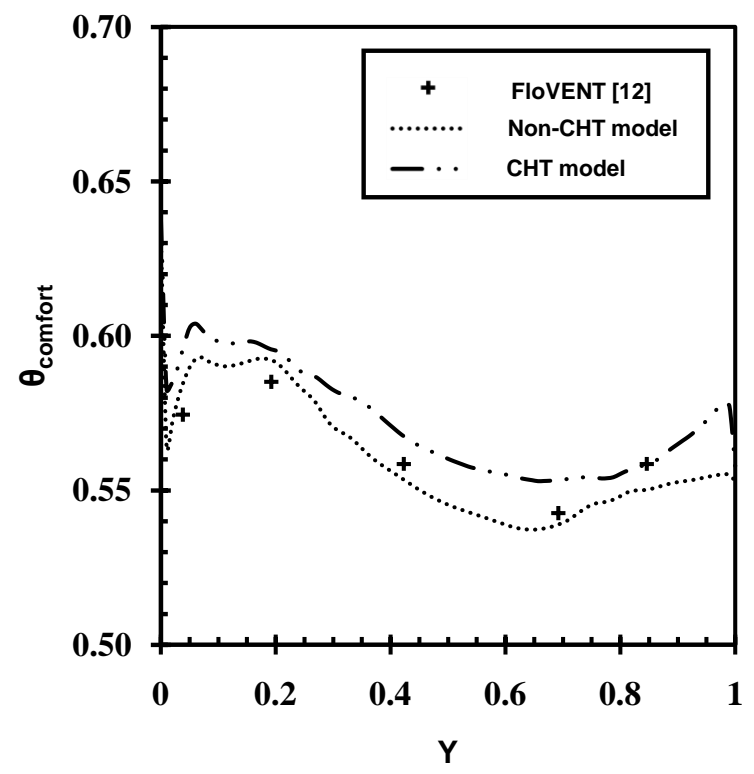

(a)

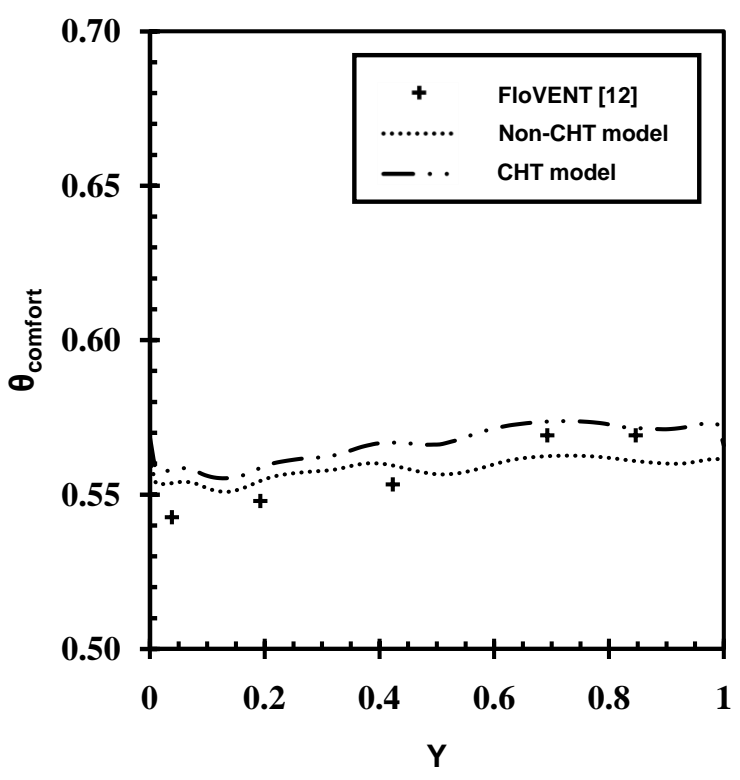

(c)

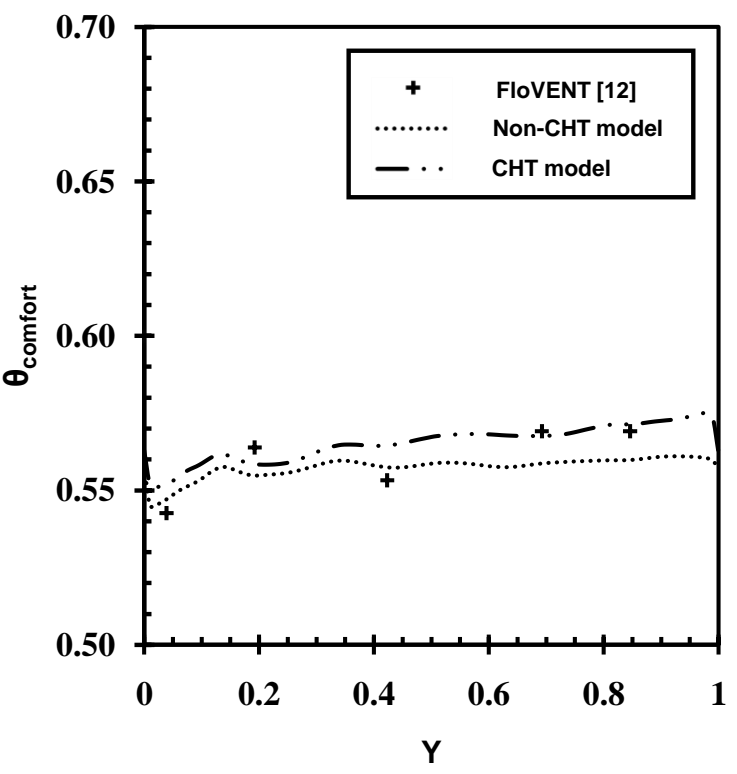

(b)

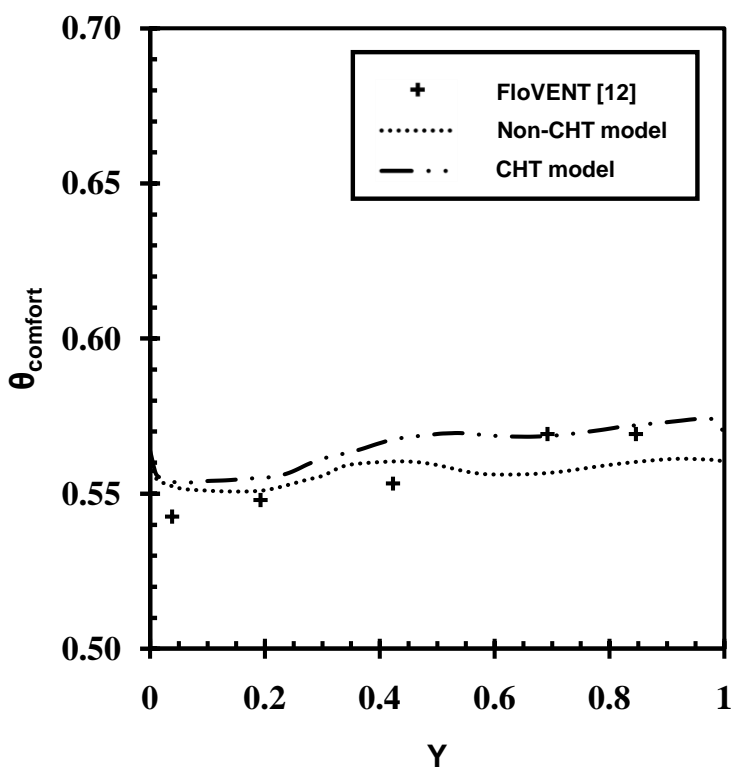

(d)

Fig. 5. Comparison of comfort temperature profile at monitoring lines (a) $P 1$, (b) $P 2$, (c) $P 3$ and (d) P4, compared with those from FloVENT [12].

Figure 6 shows comparison of fluid temperature distributions from CHT and non-CHT model cases on the solid-fluid interface $(X=0)$ at two spanwise locations of $Z=0$ and $Z=$ 0.375 . The results show that there are clear differences in temperature distributions inside 
the solid wall domain between two models. At $Z=0$ of mid-spanwise location, CHT model predicts higher temperature mainly in the bottom wall region where the heated air from the radiator panels moves upwards and meets the cold air from the inlet where a large temperature drop is observed at $Y=0.8$ location. Overall, maximum difference between CHT and non-CHT models of about $10 \%$ occurred in a region of $Y=[0,0.31]$ in the vicinity of the heat source, and this difference reduces to about $6 \%$ in a region of $Y=$ $[0.77,1.0]$ near the inlet opening location and the top wall. In the CHT model results, a nonuniform temperature distribution is observed along the window height, while non-CHT gives uniform distribution as expected. At $Z=0.375$ location near side wall, the differences between two models are very small, as the position is away from the heating panels and the inlet opening.

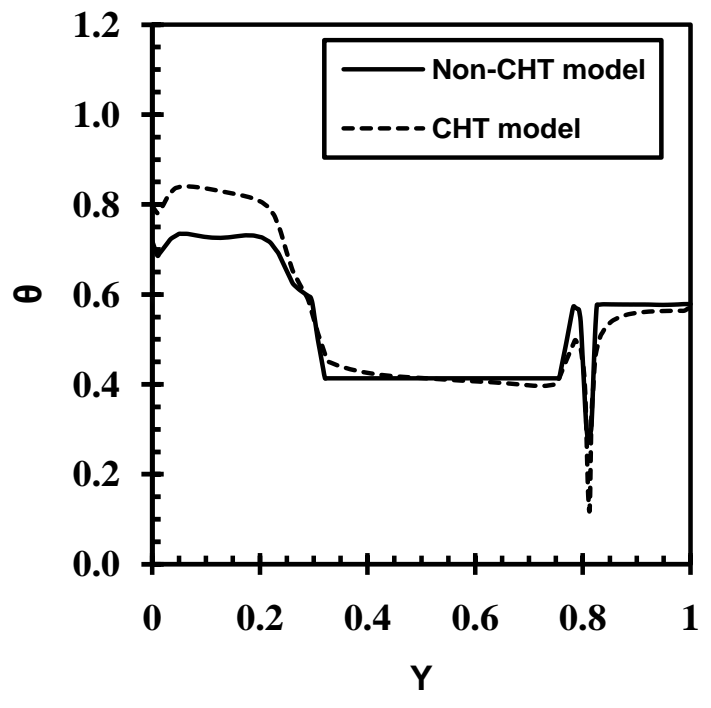

(a)

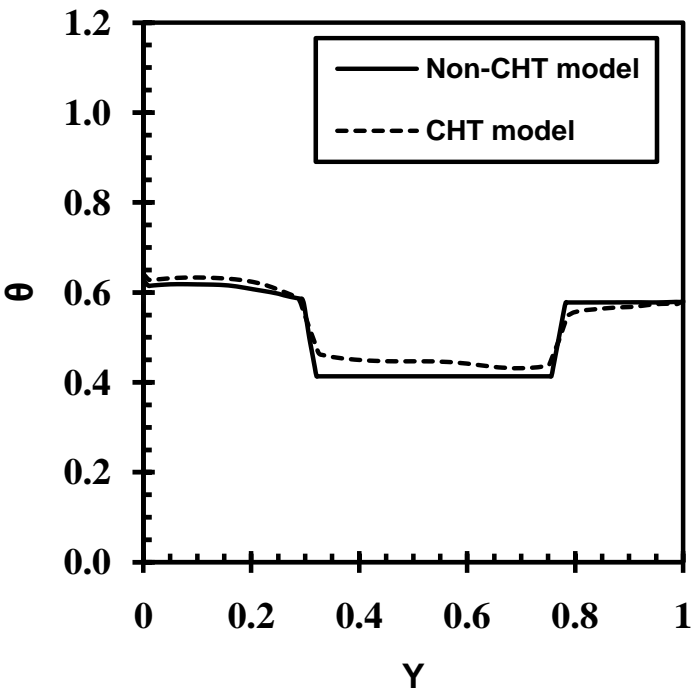

(b)

Fig. 6. Comparison of temperature variation at $X=0$ at (a) $Z=0$ and (b) $Z=0.375$

Figure 7 (a) shows the non-dimensional temperature distributions $(\theta)$ in mid-plane $(x, y, z=$ 0) throughout the solid wall domain and partly fluid domain containing the radiator, using the 
CHT model. It can be seen that the bottom part of the solid wall has been heated up by the nearby heat source (radiator), whereas cooling loads are persistent near outer wall region (due to cold environment temperature used as boundary condition) and near the inlet slot. Figure 7(b) gives non-dimensional temperature distributions inside the solid domains at three heights $\left(0.5 h_{1}, 0.5 h_{2}\right.$ and $\left.0.5 h_{3}\right)$ as seen in Figure 4 in the vertical direction on a streamwise midplane, compared with theoretical estimation based on one-dimensional heat conduction Eq. (5), i.e. $T=86.2 x+21.0$ for $0.5 h_{1}$ and $0.5 h_{3}$ positions and $T=69.8 x+14.0$ for $0.5 h_{2}$ position. It can be seen that there are good agreements between numerical predictions and theory at $0.5 h_{2}$ and $0.5 h_{3}$, corresponding to the window and the upper part of the solid wall. However, there is clear disagreement at $0.5 h_{1}$, probably due to the strong influence of the heat source on the bottom part of the solid wall, where theoretical calculation based on 1-D heat conduction equation does not consider the effect of heat source. The CHT model prediction showed that there is considerable increase in the amount of heat passing through the wall surface at the $0.5 h_{1}$ about $11.12 \mathrm{~W} / \mathrm{m}^{2}$ of wall heat flux.

Therefore it can be concluded that the predicted temperature from the CHT model with finitethickness wall is only sensitive in the area close to the heating source and the effect reduces rapidly while away from the source. 


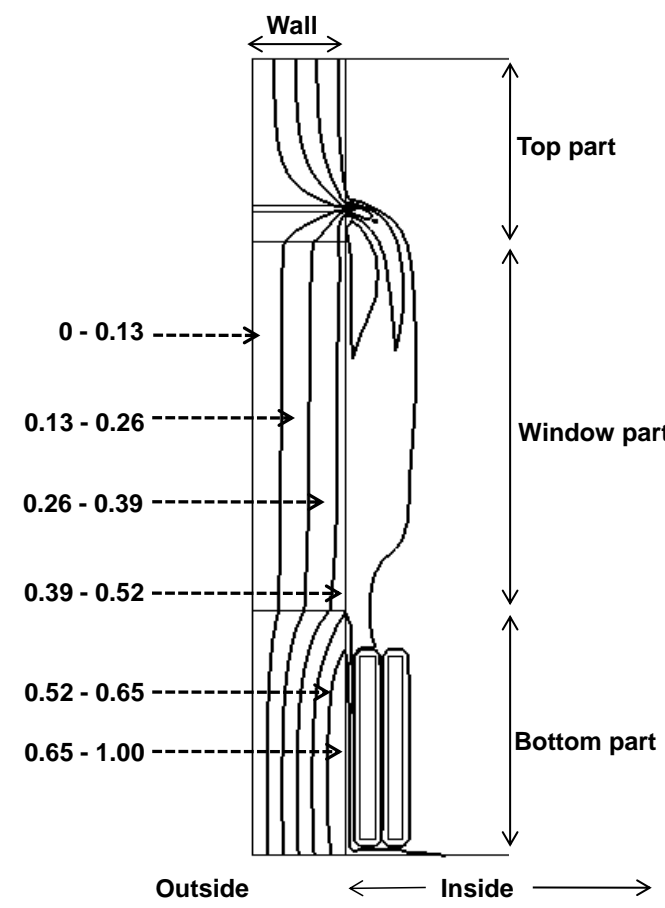

(a)

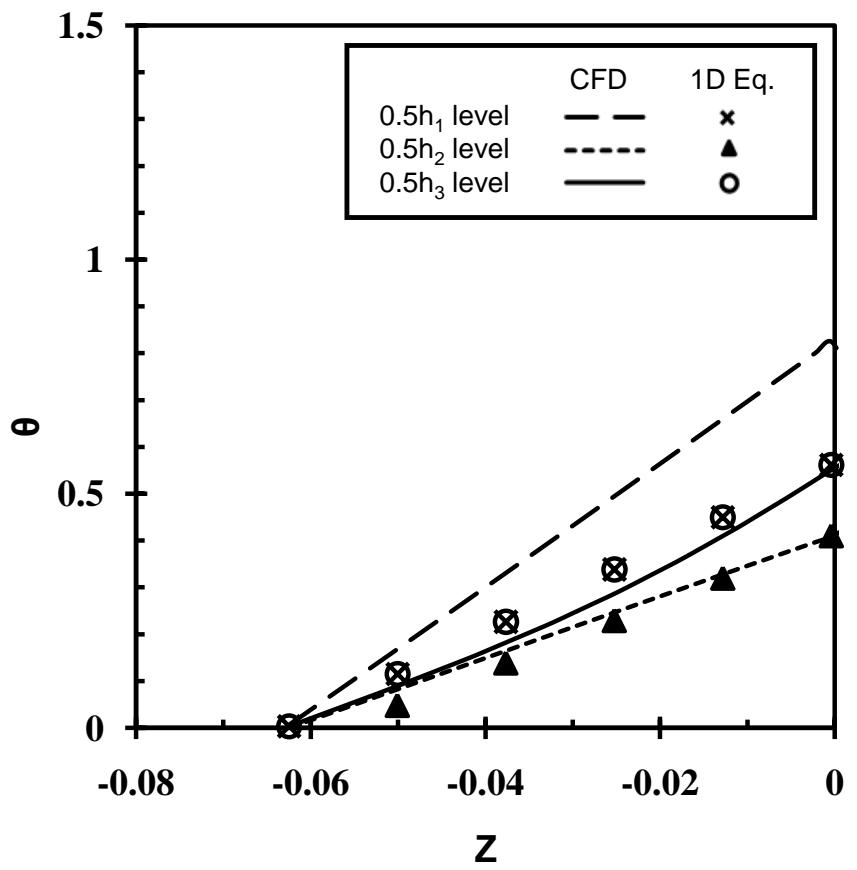

(b)

Fig. 7. Distributions of (a) isotherms $(\theta)$ in the solid wall and (b) temperature distributions at three vertical heights compared to theoretical estimation at a streamwise mid-plane by the CHT model.

\section{Results and discussion}

So far, CHT model results demonstrated its suitability to simulate the flow and heat transfer in an indoor environment. Hence, this model is further used for parametric studies discussed below.

\subsection{Design optimisation for indoor comfort}

Design optimisation aims to achieve better indoor thermal comfort, and a study has been conducted by a wide range of parameter studies, such as the arrangement of heat source and window glazing based on the CHT model room (a total of six cases), wall thickness variations (a total of two cases), and the wall material property of thermal conductivity 
sensitivity (a total of four cases), respectively (see Table 5). These parameters were chosen as close as possible to realistic domestic room conditions. For example, wall thickness of $d / H=0.042$ and 0.083 were considered, based on the minimum exterior wall thickness of detached houses and flats in the UK to have an average $U$-value of $0.22 \mathrm{~W} / \mathrm{m}^{2} K$ [40]. The wall thermal conductivity is taken from concrete, bricks and well-insulated walls, e.g. the average $U$-value for UK residential properties with a wall thickness of $0.3 m, k_{\text {air }} / k_{\text {wall }}=$ 0.12. Other geometry and boundary conditions used in above 3-D computation remained the same as the original configuration. Due to geometric constraints, in particular the heights of radiator panel $h_{B} / H=0.31$ and window glazing $h_{2} / H=0.46$, heat source is re-located at a position of $h_{A} / H=0$ on the floor wall, otherwise it remains at $h_{A} / H=0.02$ above the floor level. Also the location of window is arranged at $h_{1} / H=0.38$ from the floor wall for the case of window size of $h_{2} / H=0.38$. The results will be compared with previously validated CHT mode predictions (i.e. $h_{B} / H=0.23$ and $h_{2} / H=0.46$ ) in terms of comfort temperature and heat loss magnitude at monitoring points and on wall surfaces etc.

Table 5

Parametric case studies.

\begin{tabular}{cccc}
\hline Size arrangement study & $\begin{array}{c}\text { Wall thickness } \\
\text { study }\end{array}$ & Wall material study \\
\hline Window & Radiator & Wall thickness & $\begin{array}{c}\text { Thermal } \\
\text { conductivity }\end{array}$ \\
\hline$h_{2} / H$ & $h_{B} / H$ & $d / L$ & $k_{\text {air }} / k_{\text {wall }}$ \\
\hline 0.38 & 0.15 & 0.042 & 0.02 \\
0.46 & 0.23 & 0.083 & 0.04 \\
& 0.31 & & 0.08 \\
& & & 0.12 \\
\hline
\end{tabular}




\subsubsection{Effect of heat source and window glazing size}

Figure 8 gives comparison of heat transfer and corresponding volume-averaged comfort temperature for various heights of heat source $\left(h_{B} / H\right)$ and window glazing $\left(h_{2} / H\right)$. The heat transfer $Q(W)$ is calculated based on numerically calculated heat flux and area of the wall.

The volume-averaged comfort temperature is computed using the formula $\frac{1}{V} \int \phi d V=$ $\frac{1}{V} \sum_{i=1}^{n} \phi_{i}\left|V_{i}\right|$ where $V$ is volume. It can be seen that while the size of $h_{B}$ increases, the comfort temperature $\left(\theta_{\text {comfort }}\right)$ increases accordingly.

For a given radiator panel size $\left(h_{B} / H\right)$, the comfort temperature is lowered by about $5 \%$ for large window glazing $\left(h_{2} / H\right)$ (i.e. about $20 \%$ increase in window surface-area), due to increased heat loss through the glazing. Among three different radiator sizes, the volumeaveraged comfort temperature differs by a maximum of $5.4{ }^{\circ} \mathrm{C}$ in case of small window glazing $\left(h_{2} / H=0.38\right)$ and $6.3^{\circ} \mathrm{C}$ in case of large window glazing $\left(h_{2} / H=0.46\right)$. It is clear that using a small radiator of $h_{B} / H=0.15$ with a large window glazing $\left(h_{2} / H=\right.$ 0.46), it is difficult to sufficiently heat the entire domain, whilst it can be slightly overheated by using a large radiator $h_{B} / H=0.31$ with a small window glazing. Note that the international standards recommend the non-dimensional comfort temperature $\left(\theta_{\text {comfort }}\right)$ to be between 0.53 and 0.61 [41]. For a small-size heat source, the buoyant warm air may be too weak to heat the cold window-surface and to 'block' the cold inlet flow downward, as a result of the location of the heat source, i.e. too close to the floor. In contrast, a large-size heat source located just below the window can block the development of a cold zone near the inlet, and sometimes it may even lead to overheating. Despite thermal temperature difference at the given radiator panel size $\left(h_{B} / H\right)$, energy consumption through the radiator panels calculated using the same method described in section 4.2.2 is comparable for small and 
medium sized radiators $h_{B} / H=0.15$ and 0.23 , indicating that a large window glazing lets out more energy from the room domain. In the case of a large-size radiator $h_{B} / H=0.31$, energy loss increases by $6.4 \%$ as the window glazing size $\left(h_{2} / H\right)$ increases. There is only a small increase in heat transfer for a large-size radiator of $h_{B} / H=0.31$ with a small window glazing size $h_{2} / H=0.38$, compared with a medium-size radiator $h_{B} / H=0.23$. In the case of a medium radiator panel of $h_{B} / H=0.23$, the estimated energy consumption by the heat source is about $460 \mathrm{~W}$, while a small size radiator panel of $h_{B} / H=0.15$ consumes $22 \%$ less energy and a large size radiator panel of $h_{B} / H=0.31$ consumes $9 \%$ more energy compared to a medium size radiator.

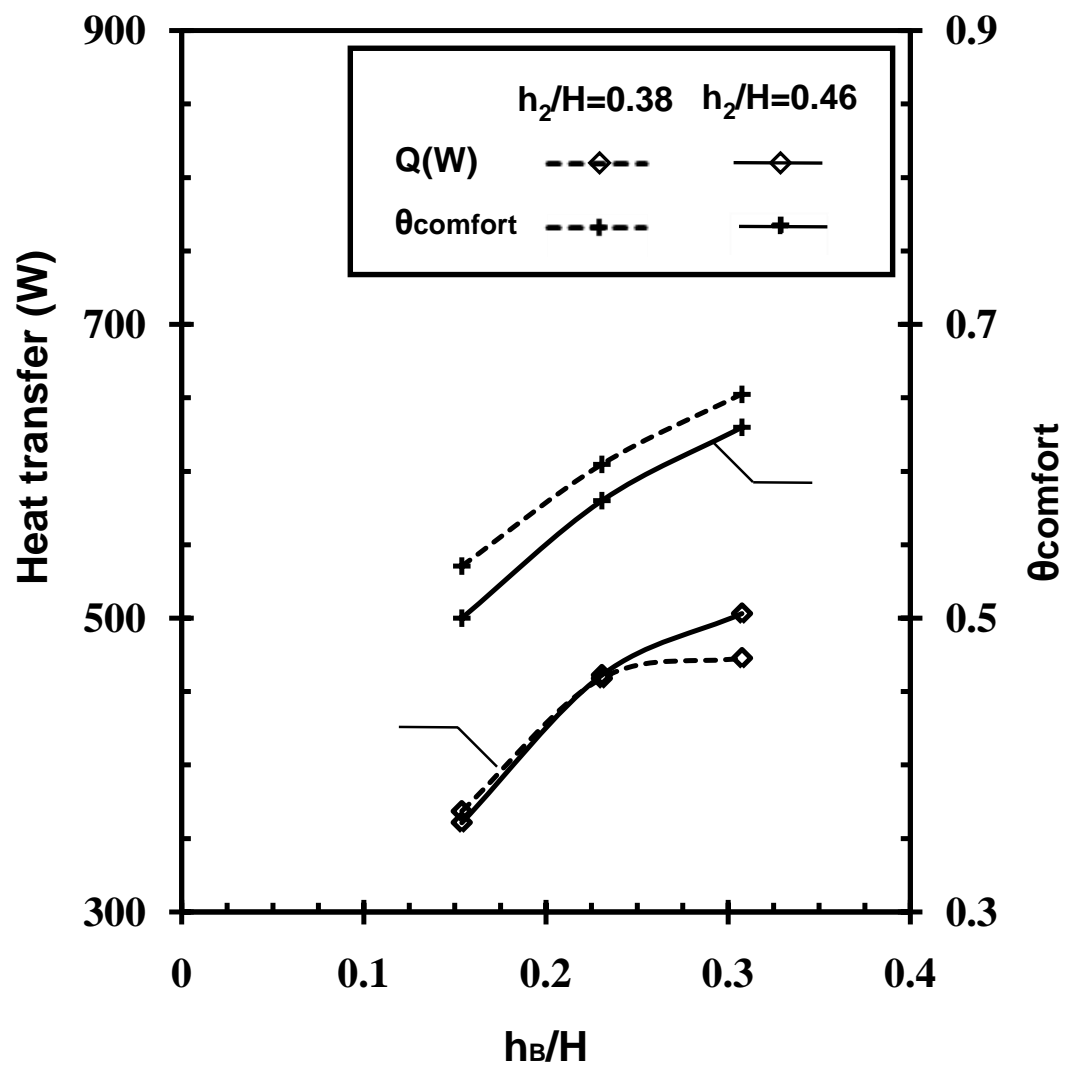

Fig. 8. Variations of heat transfer through the radiator as heat source (two bottom lines) and the corresponding comfort temperature (two top lines) for three different sizes of radiator $\left(h_{B} / H\right)$ and window glazing $\left(h_{2} / H\right)$. 


\subsubsection{Effect of wall thickness}

For a fixed radiator panel of $h_{B} / H=0.23$ and a window glazing $h_{2} / H=0.46$ arrangement, the effect of wall thickness is studied with either a thicker or thinner solid wall in comparison with the original wall thickness (i.e. $d / L=0.063$ ), applying CHT model. The resultant comfort temperature and heat transfer were derived for comparison with the original wall thickness predictions from the present study.

Figure 9 shows heat transfer rate at the solid-fluid interface $(X=0)$ of the solid wall (excluding the window glazing part) and the corresponding volume-averaged comfort temperature at given wall thickness. It can be seen that the heat transfer decreases as the wall thickness $d / L$ increases, indicating that heat loss through the solid wall would be reduced with the increase of wall thickness $d / L$ although the difference between heat transfer at $d / L=0.063$ and 0.082 is very small. Furthermore, there is more heat loss seen from the bottom section of the wall (i.e. $h_{1}$ ) due to the location of heat source. Overall, the heat loss through the bottom section of the wall is higher by about $9-22 \%$ than the upper part of the wall (i.e. $h_{3}$ ) and this contributes towards about $55-61 \%$ of the total heat loss from the solid wall. Compared with the original wall thickness $d / L=0.063$, total heat loss through the solid wall could be increased by $35 \%$ for a thinner wall $d / L=0.042$ but decreased by $12 \%$ for a thicker wall $d / L=0.082$, respectively. The corresponding heat loss through the bottom section of the wall increases by $42 \%$ for a thinner wall and decreases by $17 \%$ for a thicker wall, respectively. The non-dimensional comfort temperature is also significantly influenced by the wall thickness, resulting in an average difference value of $\theta_{\text {comfort }}=0.1$ (equivalent to a temperature difference, $\Delta T=4.6^{\circ} \mathrm{C}$ ) between thinner wall $d / L=0.042$ and thicker wall $d / L=0.083$. The comfort temperature difference in comparison to the original 
wall thickness is about $9 \%$ decrease in case of a thinner wall and $11 \%$ increase in case of a thicker wall. Overall, the comfort temperatures with thinner and original wall thickness of $d / L=0.042$ and 0.063 both satisfy the nominal building requirements, while domains with a thicker wall with $d / L=0.083$ will be slightly overheated, possibly leading to energy wastage unless radiator heating temperature is set to be at a lower level. As a result, wall thickness $d / L=0.063$ would be sufficient for indoor thermal comfort while keeping an acceptable level of heat loss, while there is a glazed window and an air inlet.

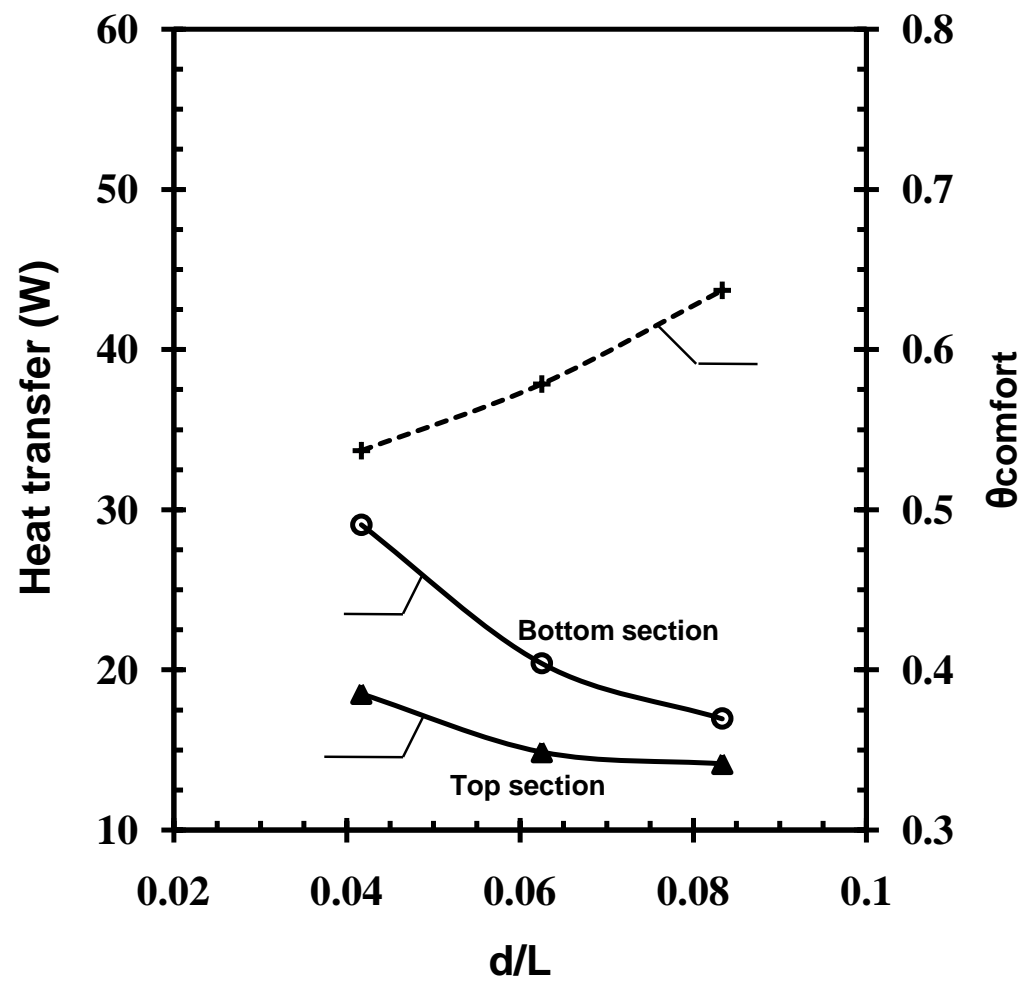

Fig. 9. Variations of heat transfer (solid lines) at solid wall surfaces and the corresponding comfort temperature (dashed line) at different wall thickness as $d / L$. 


\subsubsection{Effect of wall thermal conductivity}

Numerical studies of wall thermal conductivity effect were carried out at fixed radiator panel height, window glazing height and wall thickness of $h_{B} / H=0.23, h_{2} / H=0.46$ and $d / L=0.063$, respectively

Figure 10 gives the heat transfer rate at the solid-fluid interface $(X=0)$ of the wall and volume-averaged comfort temperature with various thermal conductivity of the solid wall. It can be seen that the comfort temperature decreases at lower thermal conductivity ratios. The difference in comfort temperature $\left(\Delta \theta_{\text {comfort }}\right)$ between $k_{\text {air }} / k_{\text {wall }}=0.02$ and 0.28 is about 0.1 , equivalent to $\Delta T=4{ }^{\circ} \mathrm{C}$ while the difference between $k_{\text {air }} / k_{\text {wall }}=0.12$ and 0.28 is reduced significantly to about 0.01 (i.e. $\Delta T=0.4{ }^{\circ} \mathrm{C}$ ) It is expected that the heat loss would be increased significantly at lower thermal conductivity ratios (i.e. $k_{\text {air }} / k_{\text {wall }}$ ). For example, the heat loss could be increased by 8 times in the bottom section of the solid wall and by 6 times in the top section of the solid wall, respectively for $k_{\text {air }} / k_{\text {wall }}=0.02$ and 0.28 (see Fig. 10). Despite the walls with $k_{\text {air }} / k_{\text {wall }}=0.08$ and 0.12 both representing well-insulated walls, there will be 2 - 3 times more heat loss compared with that of the original ratio of $k_{\text {air }} / k_{\text {wall }}=0.28$. 


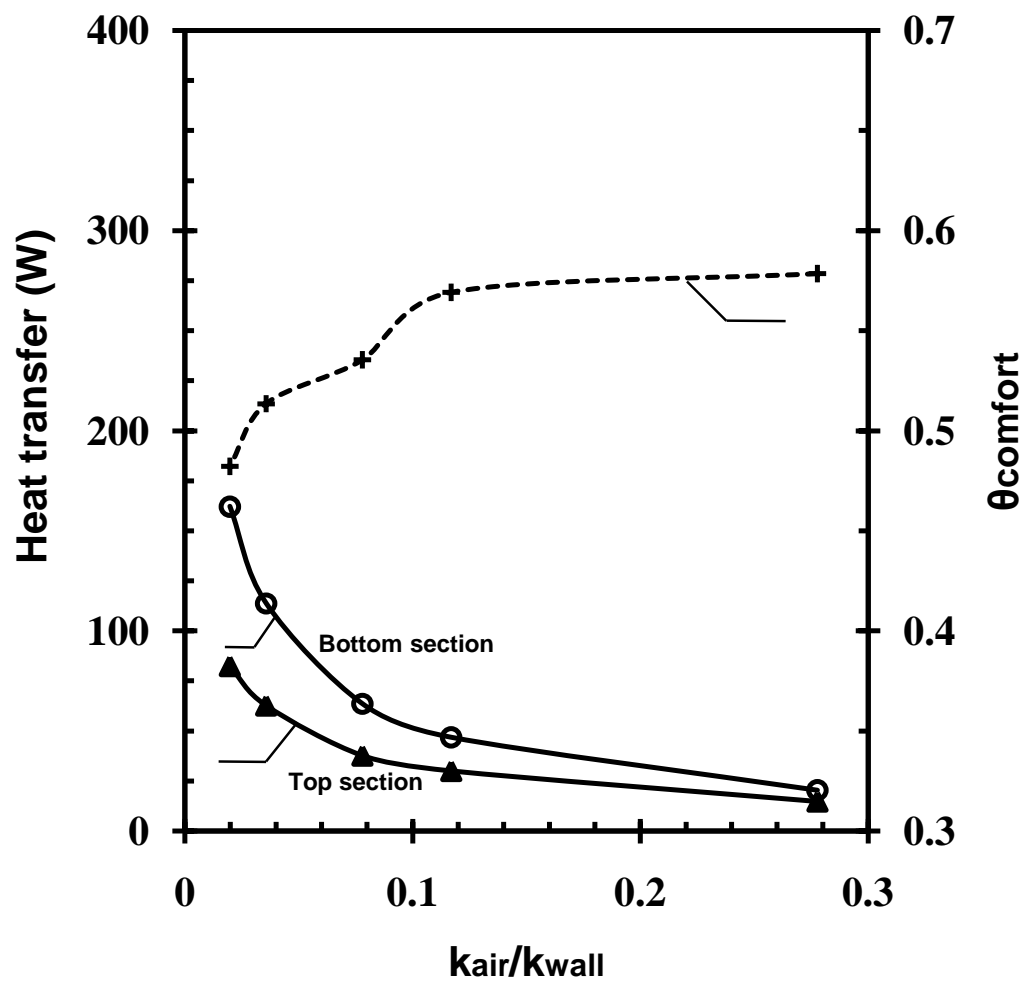

Fig. 10. Variations of heat transfer (solid lines) at solid wall surfaces and the corresponding comfort temperature (dashed line) at different wall thermal conductivity ratios $k_{\text {air }} / k_{\text {wall }}$.

\section{Conclusion}

A systematic investigation of conjugate natural convection heat transfer in a ventilated room with localised heat source and window glazing has been carried out by using a computational fluid dynamics approach, with results carefully validated against published data in literature for 2-D [5] and 3-D problems [12,16,32]. After validation, the model has been used to investigate the effects of heat source and window glazing arrangements, wall thickness and material property variation on indoor thermal performance. The results showed that the heat source and glazing sizes have significant impact on temperature field, and the wall thickness and thermal conductivity also revealed considerable impact on the level of energy consumption through the solid wall (i.e. heat loss), especially from the bottom section of the wall. The heat energy loss through the solid wall surfaces (i.e. adjacent to the radiator panels) 
was about $35 \%$ when reducing the wall thickness by $10 \mathrm{~cm}$ from the original wall thickness $30 \mathrm{~cm}$ to $20 \mathrm{~cm}$. This would reduce thermal comfort level of the domain. In fact, the volumeaveraged thermal comfort was decreased by $9 \%$ compared with that when original wall thickness was used. The large amount of heat loss is mainly influenced by the heat source being next to the solid wall without suitable insulation. With the minimum wall thickness to meet UK's domestic house requirements, the thermal comfort can be sustained within the indoor environment standards. However, the total heat loss through a thinner wall of $20 \mathrm{~cm}$ thickness is about $53 \%$ high, compared with that through a thicker wall of $40 \mathrm{~cm}$ thickness. In a model room configuration as studied here, ideal indoor thermal environment can be achievable with a radiator size of $h_{B} / H=0.23-0.31$, window glazing size of $h_{2} / H=0.38-0.46$, wall thickness of $d / L=0.042-0.063$, and thermal conductivity ratios of $k_{\text {air }} / k_{\text {wall }}=0.08-0.28$, respectively. The configuration of thinner wall $d / L=$ 0.042 and wall thermal conductivity of $k_{\text {air }} / k_{\text {wall }}=0.28$ can be applied to the region that has warmer Winter conditions. However for cold Winter conditions, a large size radiator panel, well-insulated walls, and a low wall thermal conductivity are required.

\section{Acknowledgement}

The first author would like to acknowledge the sponsorship from Mitsubishi Electric R\&D Europe MERCE-UK. 


\section{References}

[1] Kaminski DA, Prakash C. Conjugate natural convetion in a square enclosure: Effect of conductioin in one of the vertical walls. International Journal of Heat and Mass Transfer 1986;29:1979-1988.

[2] Ntibarufata E, Hasnaoui M, Vasseur P, Bilgen E. Numerical study of natural convection in habitat with direct gain passive window systems. Renewable Energy 1994;4:33-40.

[3] Ben Nasr K, Chouikh R, Kerkeni C, Guizani A. Numerical study of the natural convection in cavity heated from the lower corner and cooled from the ceiling. Applied Thermal Engineering 2006;26:772-775.

[4] Muftuoglu A, Bilgen E. Conjugate heat transfer in open cavities with a discrete heater at its optimized position. International Journal of Heat and Mass Transfer 2008;51:779-788.

[5] Kuznetsov GV, Sheremet MA. Conjugate natural convection in an enclosure with a heat source of constant heat transfer rate. International Journal of Heat and Mass Transfer 2011; 54:260-268.

[6] Bilgen E. Conjugate heat transfer by conduction and natural convection on a heated vertical wall. Applied Thermal Engineering 2009;29:334-339.

[7] Saeid NH. Conjugate natural convection in a vertical porous layer sandwiched by finite thickness walls. International Communications in Heat and Mass Transfer 2007; 32:210-216.

[8] Nouanegue H, Muftuoglu A, Bilgen E. Conjugate heat transfer by natural convection, conduction and radiation in open cavities. International Journal of Heat and Mass Transfer 2008; 51:6054-6062.

[9] Koca A. Numerical analysis of conjugate heat trasnfer in a partially open square cavity with a vertical heat source. International Communications in Heat and Mass Transfer 2008;35:1385-1395.

[10] Deng QH, TangGF. Numerical visualization of mass and heat transfer for conjugate natural convection/heat conduction by streamline and heatline. International Journal of Heat and Mass transfer 2002; 45:2373-2385.

[11] Kaluri RS, Basak T, Roy S. Heatline approach for visualization of heat flow and efficient thermal mixing with discrete heat sources. International Journal of Heat and Mass transfer 2010; 53:3241-3261. 
[12] Myhren JA, Holmberg S. Design considerations with ventilation-radiators: Comparisons to traditional two-panel radiators. Energy and Buildings 2009;41:92100.

[13] Raji A, Hasnaoui M, Bahlaoui A. Numerical study of natural convection deminated heat transfer in a ventilated cavity: Case of forced flow playing simultaneous assisting and opposing roles. International Journal of Heat and Fluid Flow 2008;29:1174-1181.

[14] Rim D, Novoselac A. Ventilation effectiveness as an indicator of occupant exposure to particles from indoor sources. Building and Environment 2010; 45:1214-1224.

[15] Krajcik M, Simone A. Olesen, B. W. Air distribution and ventilation effectiveness in an occupied room heated by warm air. Building and Environment 2012; 55:94-101.

[16] Olesen BW, Mortensen E, Thorshauge J, Berg-Munch B. Thermal comfort in a room heated by different methods. Technical paper no. 2256. Los Angeles Meeting: ASHRAE Transactions 86, 1980.

[17] Deuble, MP, de Dear RJ. Mixed-mode buildings: A double standard in occupants' comfort expectations. Building and Environment 2012; 54:53-60.

[18] Pereira ML, Graudenz G, Tribess A, Morawska L. Determination of particle concentration in the breathing zone for four different types of office ventilation systems. Building and Environment 2009; 44:904-911.

[19] Bos MA, Love JA. A field study of thermal comfort with underfloor air distribution. Building and Environment 2013; 69:233-240.

[20] Kumar A, Suman B. M. Experimental evaluation of insulation materials for walls and roofs and their impact on indoor thermal comfort under composite climate. Building and Environment 2013; 59:635-643.

[21] Buratti C, Moretti E, Belloni E, Cotana F. Unsteady simulation of energy performance and thermal comfort in non-residential buildings. Building and Environment 2013;59:482-491.

[22] Cappelletti F, Prada A, Romagnoni P, Gasparella A. Passive performance pf glazed components in heating and cooling of an open-space office under controlled indoor thermal comfort. Building and Environment 2014; 72:131-144.

[23] Tye-Gingras M, Gosselin L. Comfort and energy consumption of hydronic heating radiant ceilings and walls based on CFD analysis. Building and Environment 2012;54:1-13.

[24] Atmaca I, Kaynakli O, Yigit A. Effects of radiant temperature on thermal comfort. Building and Environment 2007;42:3210-3220 
[25] Dascalaki E, Santamouris M, Argiriou A, Helmis C, Asimakopoulos D, Papadopuolos $\mathrm{K}$ et al. Predicting single sided natural ventilation rates in buildings. Solar Energy $1995 ; 55: 327-341$.

[26] Chu HHS, Churchill SW, Patterson CVS. The effect of heater size, location, aspect ratio, and boundary conditions on two-dimensional, laminar, natural convection in rectangular channels. Journal of Heat Transfer 1976;98:194-201.

[27] Lu W, Howarth AT, Jeary AP. Prediction of airflow and temperature field in a room with convective heat source. Building and Environment 1997;32:541-550.

[28] Jin M, Zuo W, Chen Q. Simulating natural ventilation in and around buildings by fast fluid dynamics. Numerical Heat transfer, Part A: Applications, An International Journal of Computation and Methodology 2013; 64:273-289.

[29] Jiang Y, Alexander D, Jenkins H, Arthur R, Chen Q. Natural ventilation on in buildings: Measurement in a wind tunnel and numerical simulation with large eddy simulation. Journal of Wind Engineering and Industrial Aerodynamics 2003;91:331353.

[30] Betts PL, Bokhari IH. Experiments on turbulent natural convection in an enclosed tall cavity. Heat and Fluid flow 2000; 21:675-683.

[31] Horikiri K, Yao Y, Yao J. Numerical study of unstead airflow phenomena in a ventilated room. Computational Therml sciences 2012;4:317-333.

[32] Cengel YA, Ghajar AJ. Heat and mass transfer:Fundamentals and applications. Fourth edition. New York: McGraw-Hill, 2011.

[33] Chandrasekhar S. Radiative Transfer. New York: Dover Publications, 1960.

[34] Orszag SA, Yakhot V, Flannery WS, Boysan F, Choudhury D, Maruzewski J, Patel B. Renormalization Group Modeling and Turbulence Simulations. In International Conference on Near-Wall Turbulent Flows, Tempe, Arizona. 1993.

[35] Patankar SV, Spalding DB. A calculation procedure for heat, mass and momentum transfer in three-dimensional parabolic flow. International Journal of Heat and Mass Transfer 1972; 15:1787-1806.

[36] Zuo W, Chen Q. Real-time or faster-than-real time simulation of airflow in buildings. Indoor Air 2009; 19:33-44.

[37] Antonelli M, Mazzino A, Rizza U. Statistics of temperature fluctuations in a buoyancy-dominated boundary layer flow simulated by a large eddy simulation model. Journal of Atmospheric Sciences 2003; 60:215-224. 
[38] Myhren JA, Holmberg S. Comfort temperature and operative temperature in an office with different heating methods. In Proceeding of the Health and Buildings: Indoor Climate, Portigal 2006; 2:47-52.

[39] ANSYS 13.0 Fluent. Theory manul: Radiation temperature.

[40] Department for Communitires and Local Government, GOV.UK, Building regulations: Energy efficiency requirements for new dwellings, Department of communities and local government. London 2007 (www.communities.gov.uk).

[41] ISO 13370, International standard, Thermal performance of buildings - Heat transfer via the ground - Calculation methods. 2007 (www.iso.org). 